\title{
Thermal-Mechanical Stress Analysis of Pressurized Water Reactor Pressure Vessel with/without a Preexisting Crack under Grid Load Following Conditions
}

\author{
Subhasish Mohanty ${ }^{1 *}$, William K Soppet ${ }^{1}$, Saurin Majumdar ${ }^{1}$ and Krishnamurti Natesan ${ }^{1}$ \\ ${ }^{1}$ Nuclear Engineering Division, Argonne National Laboratory, Lemont 60439, USA \\ ${ }^{*}$ Corresponding author Tel: 630-252-5137, Email: smohanty@anl.gov
}

\begin{abstract}
In this paper, we present thermal-mechanical stress analysis of a pressurized water reactor pressure vessel and its hot-leg and cold-leg nozzles. Results are presented from thermal and thermal-mechanical stress analysis under reactor heat-up, cool-down, and grid load-following conditions. Analysis results are given with and without the presence of preexisting crack in the reactor nozzle (axial crack in hot leg nozzle). From the model results it is found that the stressstrain states are significantly higher in case of presence of crack than without crack. The stressstrain state under grid load following condition are more realistic compared to the stress-strain state estimated assuming simplified transients.
\end{abstract}

\section{INTRODUCTION}

Use of renewable energy such as solar and wind has increasingly become a worldwide goal to avoid catastrophic climate change. Widespread availability of clean, affordable, and reliable energy would also be a cornerstone of the world's increasing prosperity and economic growth [1]. However, such renewable energy sources are only intermittently available and cannot reliably be used for base-load demand.

In many countries such as the U.S., France, South Korea, and Japan, nuclear energy is extensively used as a base-load source of electricity. However, when more and more renewable energy sources are connected to the electric grid, a question arises: do the nuclear power plants (NPPs) have the ability to adjust to a varying load from the interconnected grid, including daily and seasonal variations [2-10]? Under the load-following mode, the pressure boundary components of NPPs may be subjected to additional thermal-mechanical cycles, particularly when the fluctuation in the gap between the grid demand and renewable energy supply is severe (in terms of both frequency and amplitude). Although most modern nuclear plants are designed to follow grid demands to a certain extent through consideration of a large safety factor, no study (at least none reported in the open literature) has been undertaken to determine the stress-strain state of reactor components under grid-load following. Most previous research on NPP component safety assessment, including our own [11-12], is based on a stress analysis of components using simplified design transients. For accurate structural integrity assessment of NPP components, it is necessary to perform structural fatigue evaluation under more realistic loads [13-15]. In this regard, thermal-mechanical stress analysis of NPP components under the grid load-following mode might be necessary for accurate fatigue evaluation. In addition, since there are plans for increasing the life of current NPPs from their original design life of 40 years to the extended life of 80 years, 
aging-related material issues $[16,17]$ can play additional detrimental role in the structural integrity of NPP components.

Argonne National Laboratory (ANL), under the sponsorship of the Department of Energy's Light Water Reactor Sustainability (LWRS) program, has been involved with extensive material testing $[18,19]$ and mechanistic modeling $[11,12,32]$ for assessing the structural integrity of NPP components under design and extended service conditions. In this paper we present detailed results from thermal mechanical stress analysis of a reactor pressure vessel (RPV) and its nozzle (both with and without preexisting crack) under typical reactor heat-up, cool-down, and load-following modes. The details of the proposed framework and related results are discussed below.

\section{FINITE ELEMENT MODEL OF REACTOR PRESSURE VESSEL AND NOZZLES}

We developed finite element (FE) models for both heat transfer analysis and for subsequent thermal-mechanical stress analysis. In our earlier work $[11,12]$ we presented a preliminary/skeletal FE model of an overall reactor consisting of a reactor pressure vessel, hot leg, cold leg, and steam generator. In this work, we present a detailed FE model of the reactor pressure vessel and its nozzle only. The major aim was to perform a stress analysis under realistic thermal-mechanical loading such as under grid load-following conditions and to study the stress-strain state of the RPV and its nozzles with/without the presence of crack. The details of the FE model are discussed below.

The models were developed by using commercially available ABAQUS FE software [20]. The FE models are based on approximate geometry determined from publicly available literature $[16,21-24]$. The RPV model includes a typical two-loop pressurized water reactor with two hotleg (HL) nozzles and 4 cold-leg (CL) nozzles. Figure 1 shows the outer/inner diameter (OD/ID) surface of the RPV and its HL and CL nozzles. For the requirement of modeling cracks, 3D models were developed and meshed by using eight nodded 3D brick elements. In our previous work [11, 12] we found that eight-node linear elements (DC3D8) were sufficient to model heat transfer compared to a computationally expensive counterpart of 20-node brick elements (DC3D10). For stress analysis, the corresponding C3D8, 8-node linear elements were used. Note that in our earlier work [11, 12], we considered other components such as the HL, CL, and steam generator; in the present work, however, we have not considered those components to reduce the computational burden by limiting the number of finite elements. Instead, we included detailed geometry of HL/CL nozzles and increased the number of elements along the thickness direction to allow modeling of preexisting cracks. Furthermore, in our previous work our intention was to perform preliminary system level FE model to estimate the typical stress-strain and displacement states under simplified design transients. However, in the present discussed work we present stress-analysis results under more realistic transients such as under grid load-following conditions and with/without presence of crack. In addition, compared to our earlier model (for which HL and CL nozzles were not included), we included detailed HL and CL nozzles to the FE model of RPV. Figure 2 shows the OD and ID surface of the RPV and it nozzle FE mesh. A finer mesh was selected near the nozzle area for modeling possible stress hot spots arising due to the presence of openings, such as nozzles and preexisting cracks. The RPV and nozzle assembly have a total of 72,977 DC3D8 elements for heat transfer models or C3D8 elements for structural analysis models. The materials properties of 508 low alloy steel (508 LAS) is used for the FE modeling of all the sections of the RPV and its nozzles. 


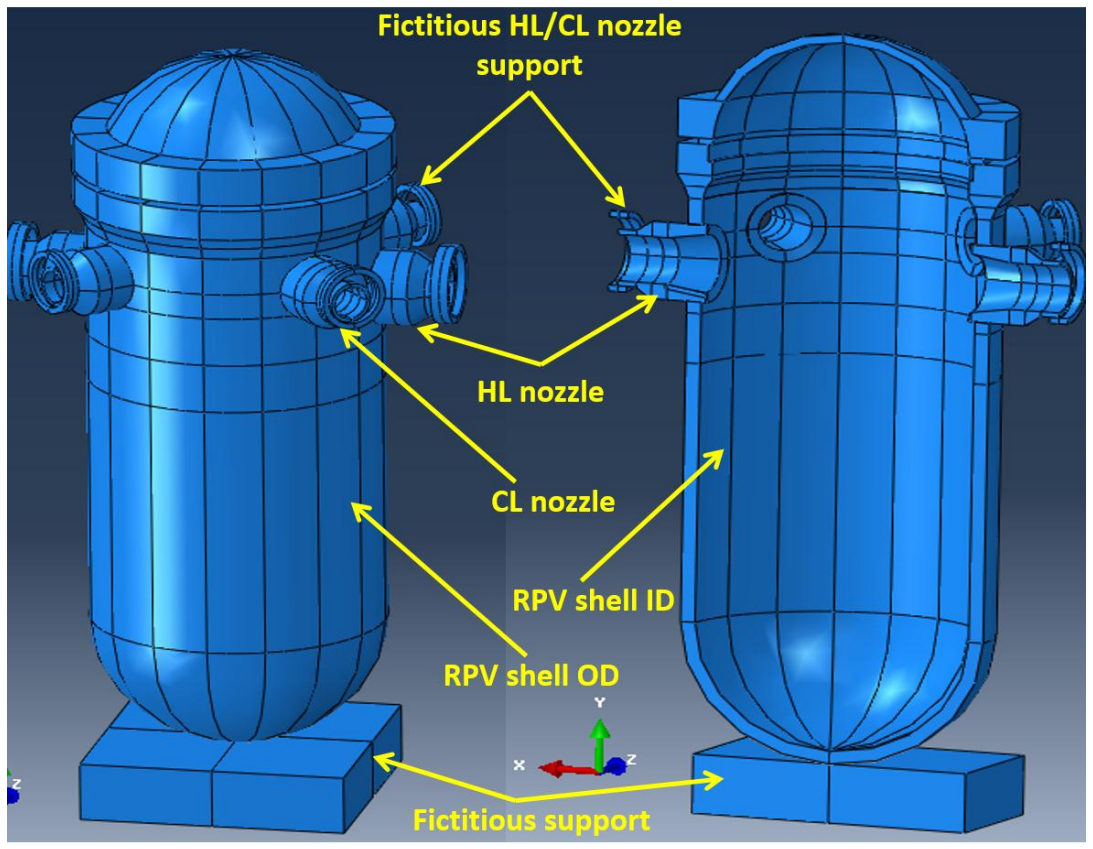

Figure 1 Solid model of RPV and its nozzle.

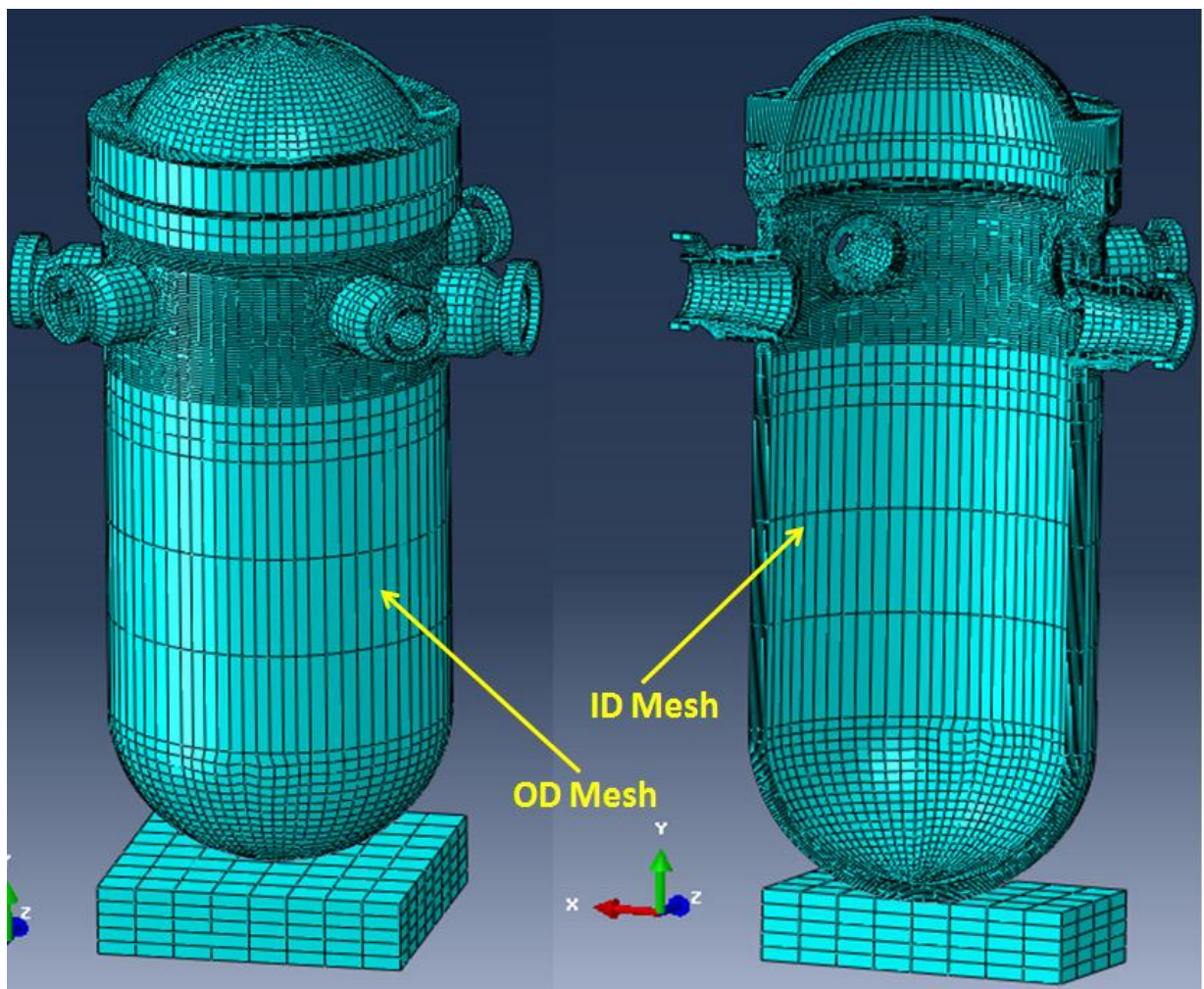

Figure 2 RPV and its nozzle FE mesh.

For simulating the realistic stress state of reactor components, it is necessary to model prototypical displacement boundary conditions. For example in a typical Siemens designed PWR, the RPV is supported at its bottom end by an inverted frusto-conical surface concentric with the 
axis of the vessel and fixed to its bottom [36]. This surface rests on an upright frusto-conical surface which is also concentric with the vessel's axis. Radial thermal displacements of the RPV's bottom section results in diameter changes in the frusto-conical surface fixed to its bottom so that this surface by cam action slides up and down on the bottom frusto-conical surface. With a properly defined angularity between upper and bottom frusto-conical surfaces, compensates the vertical thermal expansion of the vessel which occurs simultaneously with its radial expansion. In another example, for a Westinghouse designed reactor the main coolant flow nozzles (both hot and cold legs) serve as vessel supports in addition to performing their primary function as conduits [37]. The support nozzles rest on integral pads which allow free thermal expansion of RPV. However, for simplicity in the work discussed in this paper, the details of the real reactor supports or boundary conditions were not considered, rather simplified boundary constraints for reactor supports were modeled as shown in Figure 1. For example, the HL and CL nozzles displacement boundary conditions were modeled such a way that would allow thermal expansion in all the direction of the nozzle section similar as prototypical conditions. For the purpose, ring-shaped fictitious HL/CL nozzle supports (refer Figure 1) were modeled and general contact condition selected between ID surface of nozzle support and OD surface of nozzles. The nozzles were constrained to RPV using tie constraints. Whereas, the bottom section of the RPV was tied to a base plate, which was attached to the ground and constrained in both horizontal and vertical directions. This displacement boundary conditions allowed the RPV to freely expand in the vertical direction due to temperature change. Note that to avoid rigid body motion related computational issues, a general contact relation was not modeled between the bottom sections of RPV and top section of the base plate. Rather the bottom section of the RPV was tied to the top section of the base plate allowing free thermal expansion of RPV only in the vertical direction. However, note that the above boundary conditions are simplified assumptions and do not necessarily represent the exact boundary conditions in a real reactor. In addition, in the present assembly-level model, we did not consider the plane of symmetries because to model crack in one of the HL nozzles. In addition to modeling the reactor temperature and pressure cycle, the dead load associated with reactor coolant water and the self-weight of RPV and its nozzles were considered for the stress analysis models.

In addition, a typical RPV is subjected to substantial gravity load associated with the reactor internals. The approximate loads due to these internals are also included in the FE model as additional gravity load. Based on the data given in reference [25], in the discussed model, the upper and lower internal weights were considered as 50,000 kg and $120,000 \mathrm{~kg}$, respectively. From the FE model, the volume of the RPV and nozzle was estimated as $37.6 \mathrm{~m}^{3}$. Assuming $50 \%$ of this volume is occupied with reactor coolant water, the weight of the coolant water was estimated to be $18,800 \mathrm{~kg}$. Using ABAQUS, we performed a frequency/modal analysis to estimate the selfweight of the RPV and its nozzles. This parameter was estimated as $325,663 \mathrm{~kg}$. The total dead weight (including self-weight of RPV and internals and weight due to coolant) was estimated to be $514,463 \mathrm{~kg}$. This total weight was modeled as distributed gravity load, with an artificial gravity constant ( $g_{\text {artificial }}$ ) estimated through the following relation:

$$
\mathrm{g}_{\text {artificial }}=\frac{\text { mass }_{\text {self }}}{\text { mass }_{\text {total }}} \mathrm{g}_{\text {actual }}=\frac{514,463}{325,663} 9.81=15.497 \mathrm{~m} / \mathrm{sec}^{2}
$$




\section{TEMPERATURE-PRESSURE LOADING CONDITIONS UNDER HEAT-UP, COOL- DOWN, AND GRID-LOAD FOLLOWING}

The heat transfer and structural analysis requires an appropriate temperature and pressure (T-P) boundary condition as input to the FE model. These inputs can be obtained through performing system-level thermal-hydraulic and computational fluid dynamics (CFD) analysis. Performing system-level (with all reactor internals) thermal-hydraulic and CFD analysis is highly complex, computationally intensive, and not the major focus of our work. Hence, we used an approximate T-P boundary condition estimated based on literature data. In the present work we considered one reactor operation cycle comprising heat-up, normal operation under grid load following, and cool-down conditions. The estimation of associated T-P boundary conditions is briefly described below.

\section{Reactor Heat-up and Cool-down}

In the present work we have used the heat-up and cool-down T-P profile given by the Electric Power Research Institute (EPRI) [26, 27]. The respective temperature and pressure profiles based on EPRI literature are shown in Figures 3 and 4. Similar T-P profiles are also used for the Électricité de France (EDF) reactor heat-up and cool-down [28].

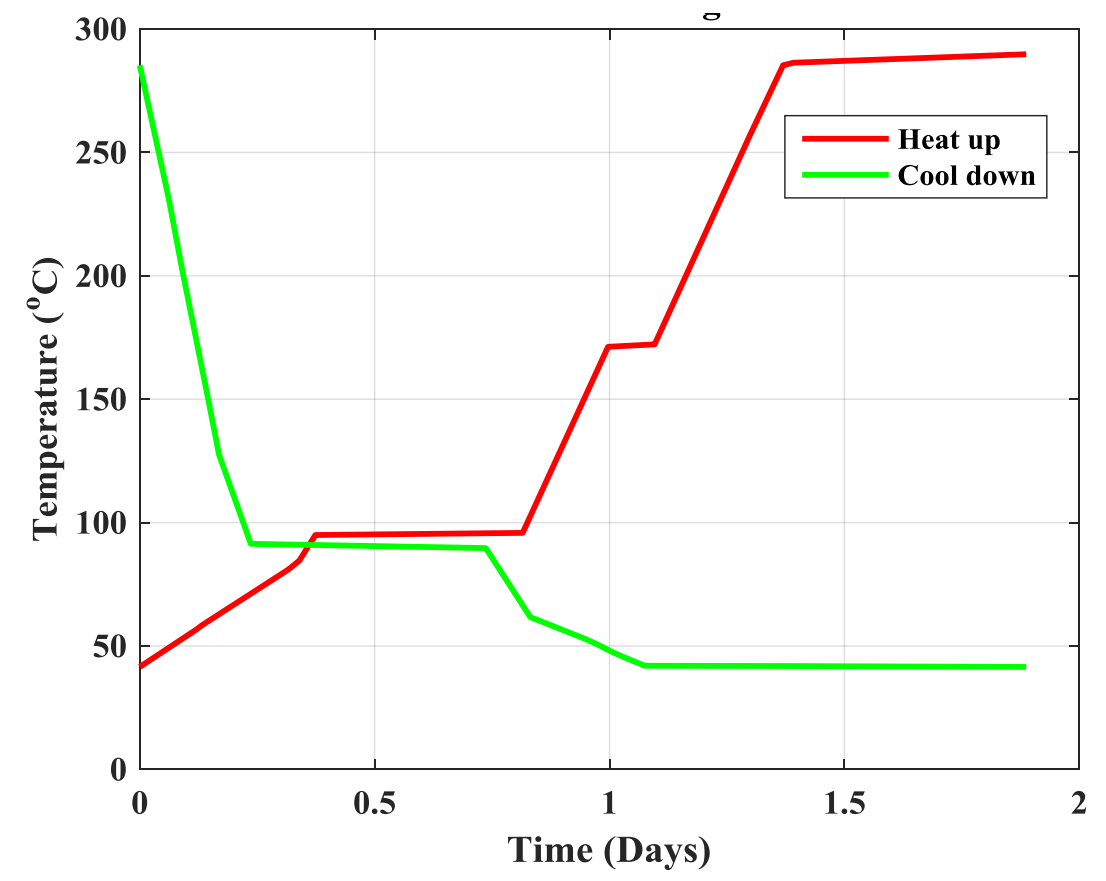

Figure 3 Temperature profile during reactor heat-up and cool-down [26, 27]. 


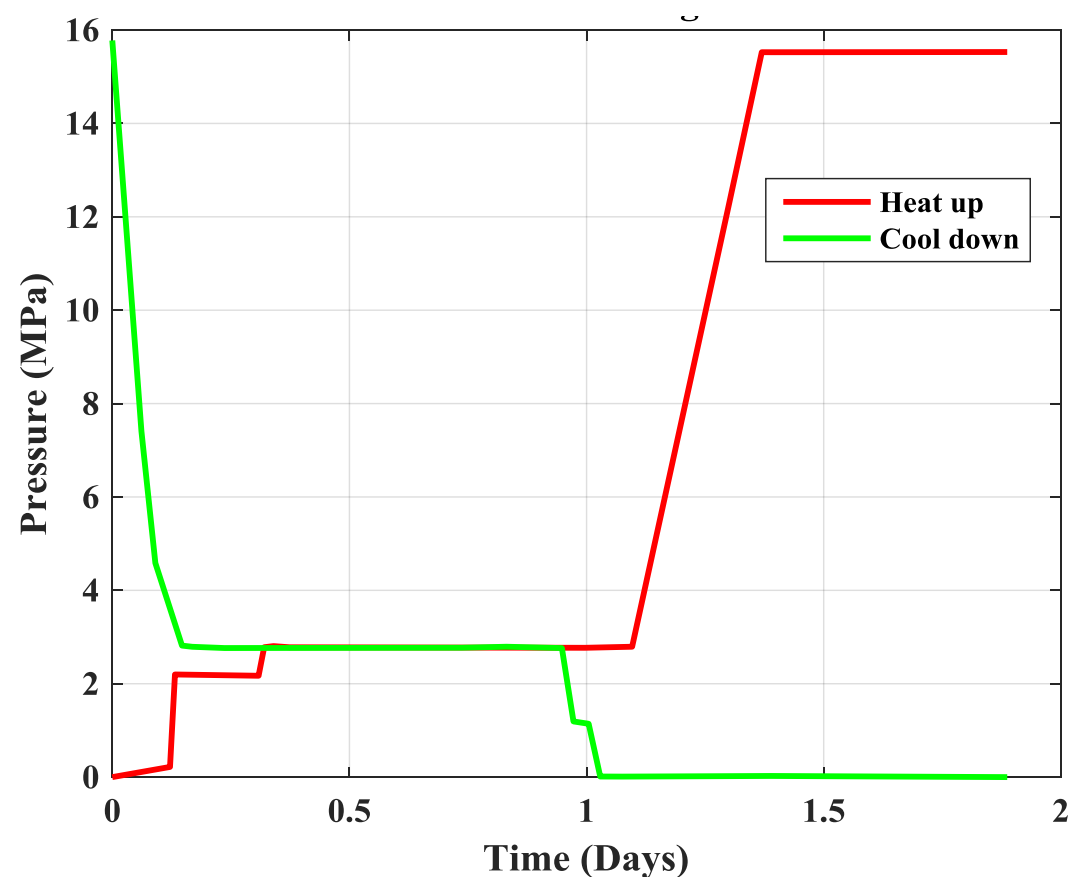

Figure 4 Pressure profile during reactor heat-up and cool-down [26, 27].

\section{Reactor Power Operation under Load Following}

After hot standby (at end of heat up operation), the reactor is powered up by following a procedure to reach its rated or maximum operating power. Although the absolute value of the rated or maximum operating power varies from reactor to reactor, it is not expected that the reactor would operate under a perfect steady-state condition. Under a realistic scenario the reactor power would fluctuate, depending on the grid demand. Hence, it is essential to incorporate these power fluctuations and associated temperature-pressure variation in the FE model of a reactor component for accurate evaluation of its stress-strain state. In the present work the power-following condition of an EDF pressurized water reactor is considered.

The power-following time plot for a typical EDF reactor operation cycle can be found from references (refer Figure 1 of [2] or Figure E.1 of [3]). The given history in those reference has hundreds of peaks (both small and large). Modeling all these peaks in the FE model is time consuming and unnecessary. Hence, only approximately 300 representative peaks were considered from the original EDF power-following time data. Figure 5 shows the simplified percentage power time plot considered for the present FE model. The literature [2,3] also gives approximate temperature variations in the HL and CL of an EDF reactor with respect to percentage power. Using the percentage power history shown in Figure 5 and power versus temperature relation given in $[2,3]$, we estimated the approximate temperature history in the HL and CL during power operation. Figure 6 shows the corresponding, estimated temperature histories in HL, CL and the average of $\mathrm{HL}$ and CL temperatures. For FE models, we need the temperature boundary condition during heat-up and cool-down conditions. To that end, the heat-up and cool-down history shown in Figure 3 was combined with the temperature history shown in Figure 6 to estimate the HL and CL temperature boundary conditions under a single loading cycle comprising a heat-up, power operation, and cool-down sequence. Note that during the heat-up and cool-down procedure, it is assumed that the CL and HL follow the same temperature-time plot. Figure 7 shows the estimated 
temperature for the HL and CL over a single reactor loading (or fuel) cycle. This temperature history was used in the discussed FE model as the temperature boundary condition. The HL temperature history was used to model the ID surface temperature of the HL nozzles, whereas the CL temperature history was used to model the ID surface temperature of the CL nozzles. The temperature of the ID surface of the RPV was assumed to be similar to that of the CL. Furthermore, similar to the full-cycle temperature history, a full-cycle pressure history was estimated to model the ID surface pressure boundary condition of the RPV, HL, and CL. Unlike the temperature history during power operation, the pressure was assumed to be fixed and equal to the hot standby condition. Figure 8 shows the estimated combined pressure history during a single reactor loading cycle. This pressure history was used to model the ID surface pressure boundary condition of the $\mathrm{HL}, \mathrm{CL}$, and RPV.

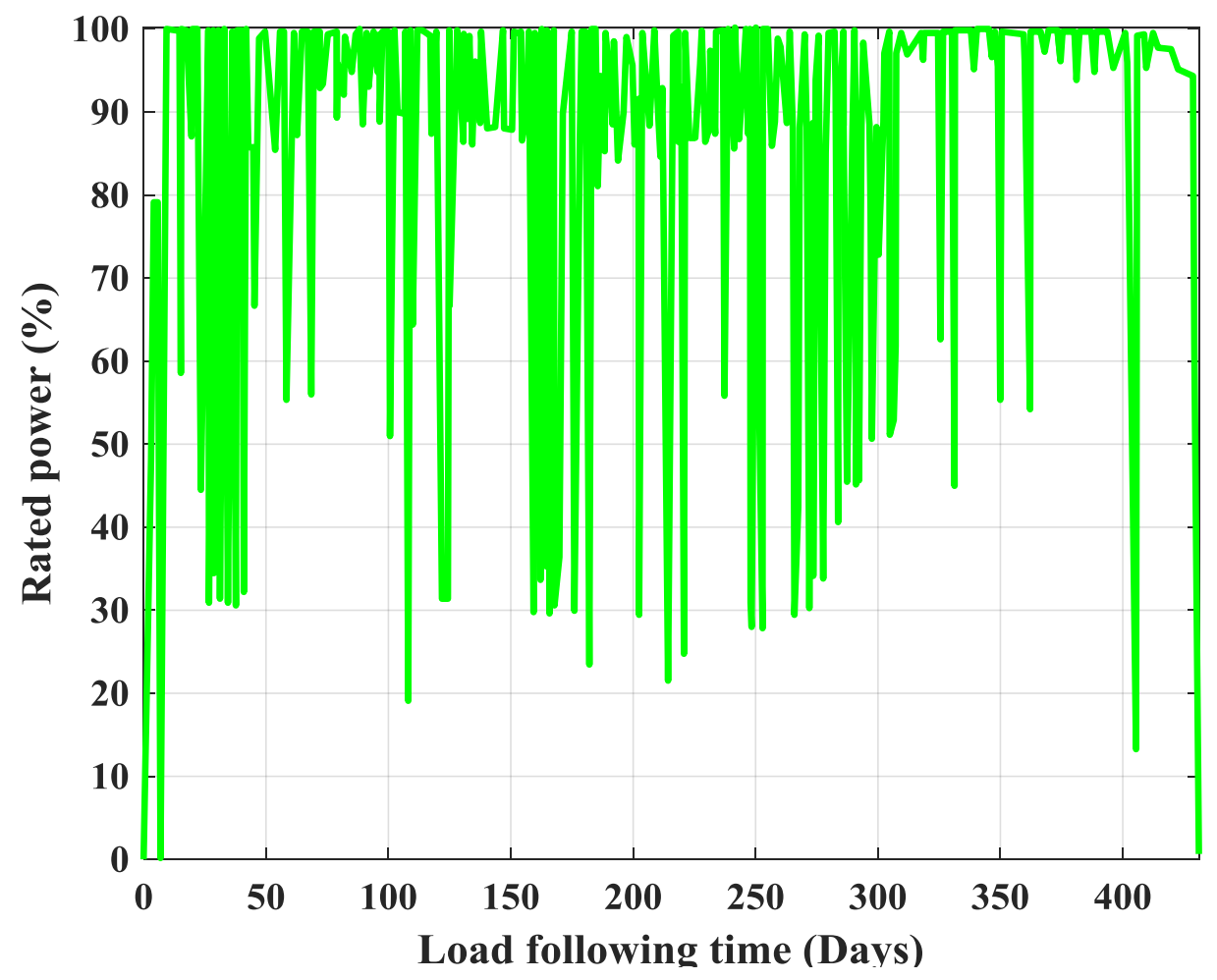

Figure 5 Simplified percentage power history considered for present FE model. 


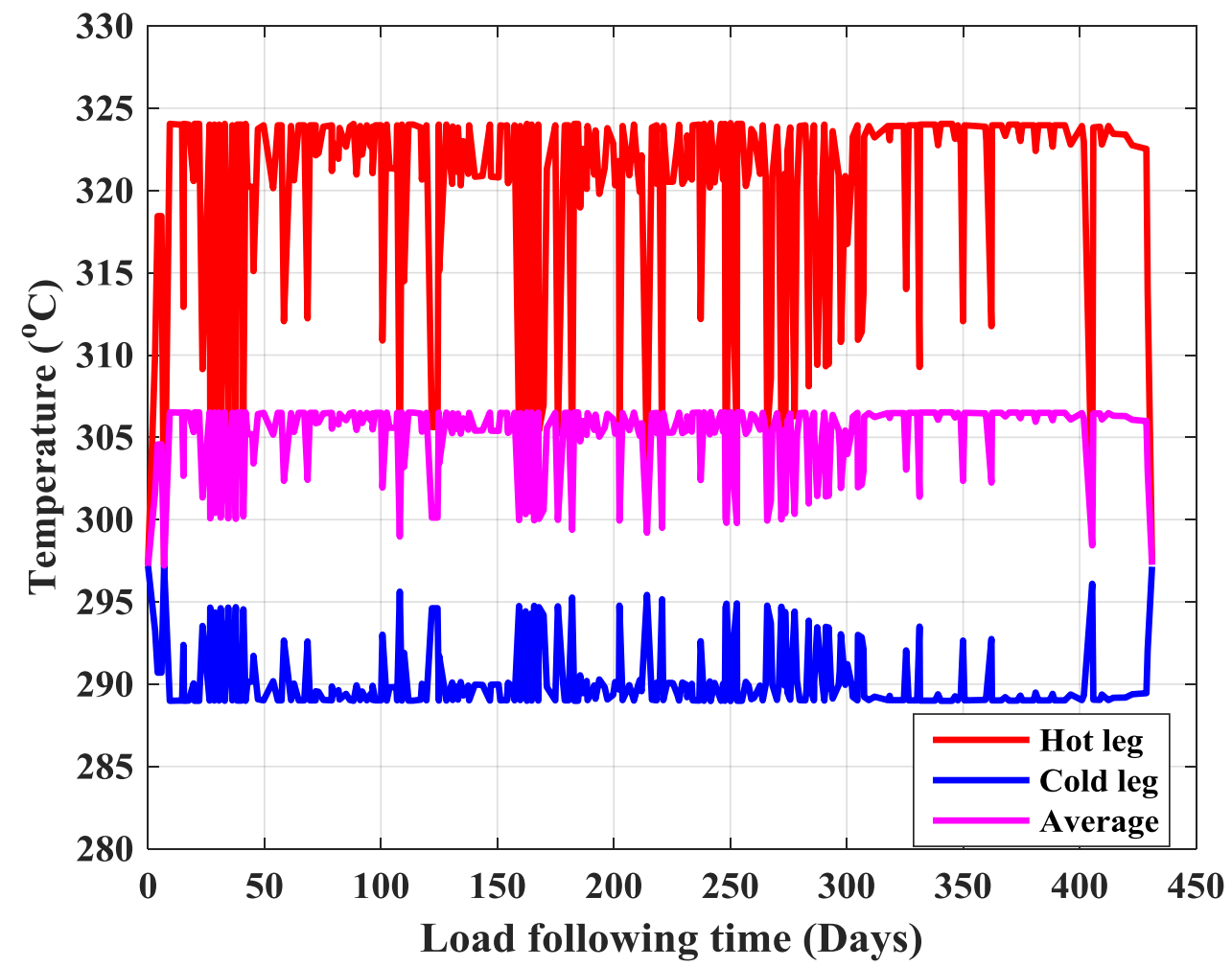

Figure 6 Approximate estimated temperature histories in HL and CL and their average during normal power operation under grid-following mode.

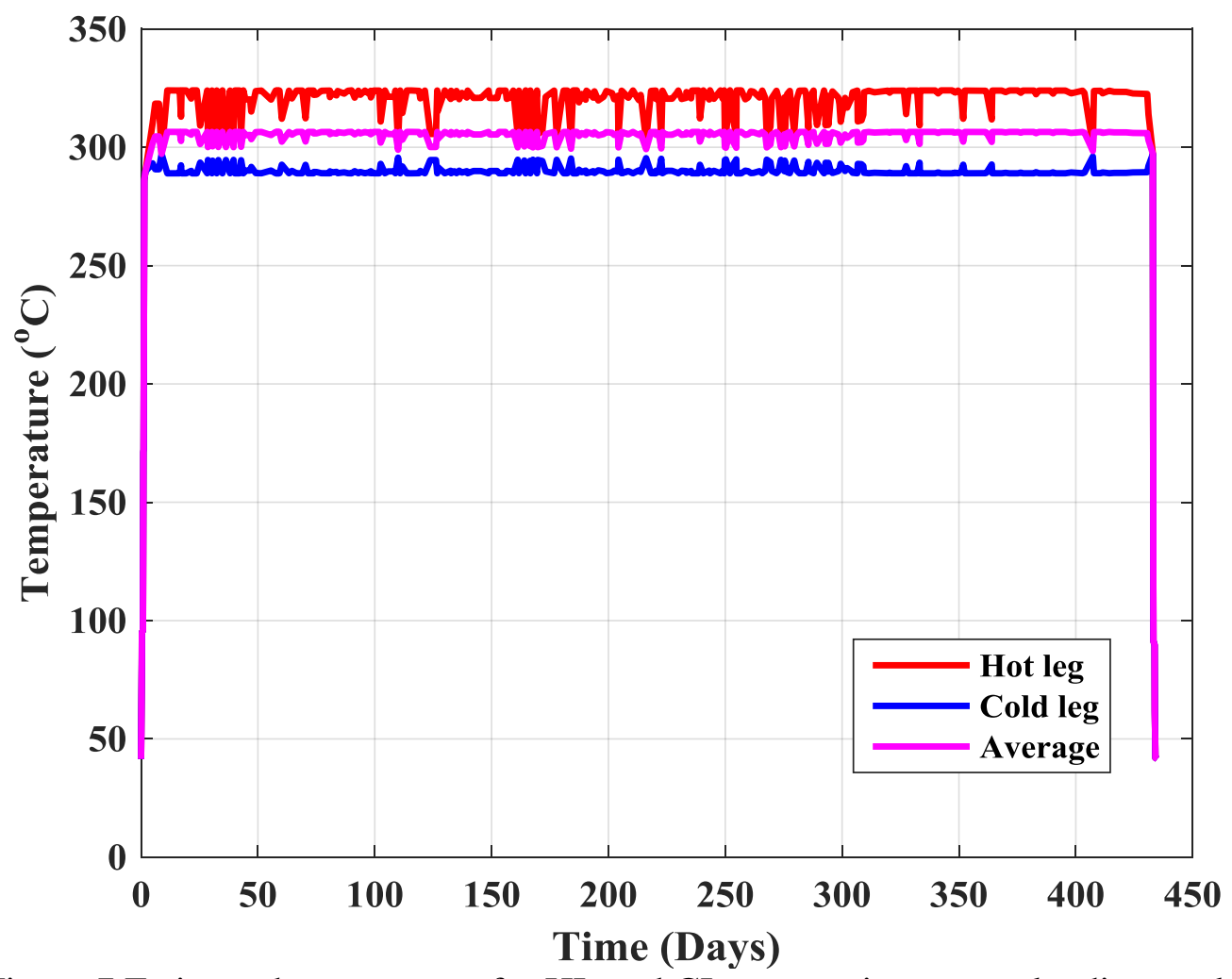

Figure 7 Estimated temperature for HL and CL over entire reactor loading cycle. 


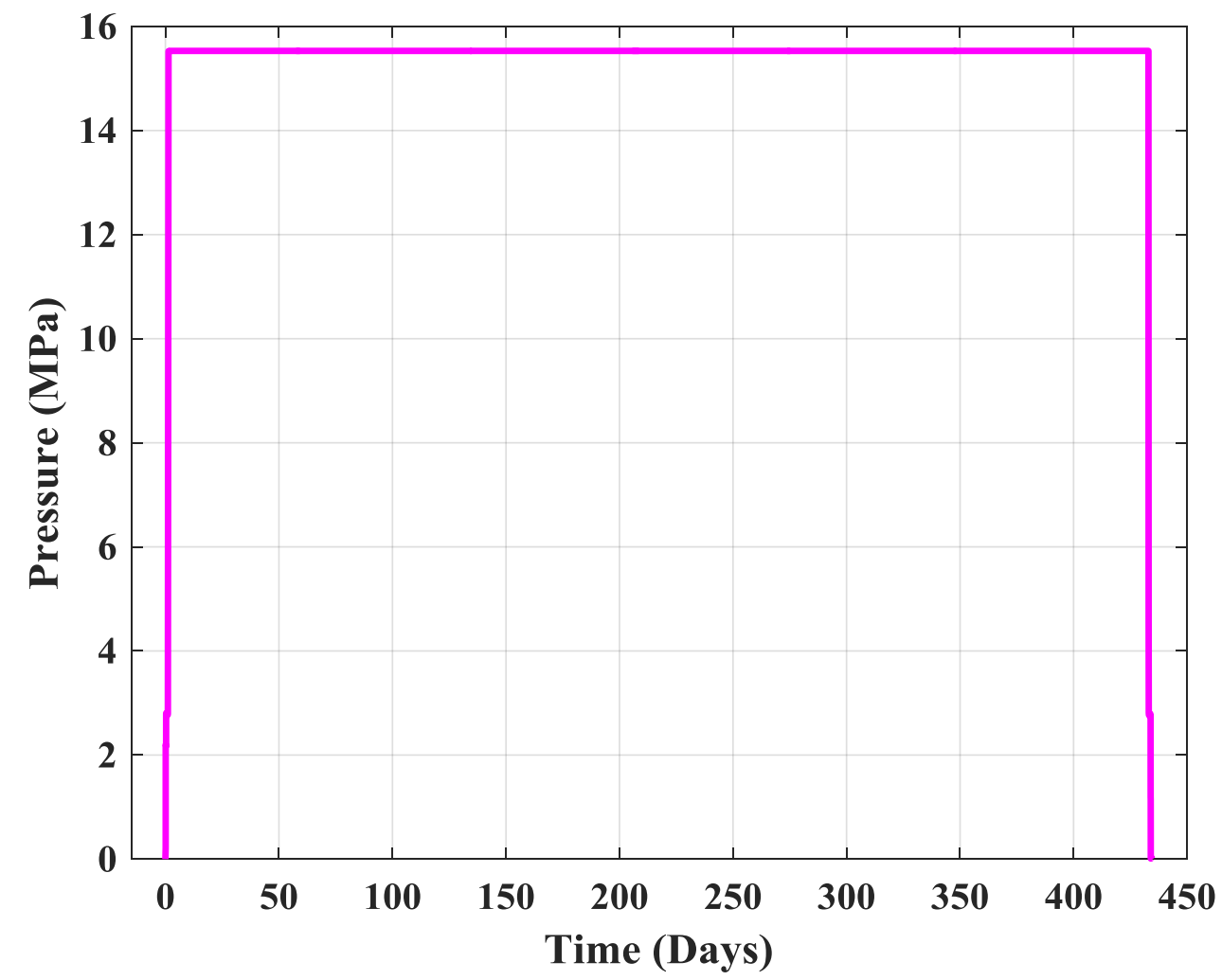

Figure 8 Estimated combined pressure history during complete reactor loading cycle.

\section{HEAT TRANSFER ANALYSIS OF RPV AND NOZZLES}

Using the FE model discussed earlier, we performed a heat transfer analysis for the RPV. The analysis was performed to estimate nodal temperature across the RPV and HL/CL nozzle thickness. These data can then be used for the thermal-structural stress analysis. For heat transfer analysis we used a heat transfer coefficients with maximum value of $18502.8 \mathrm{~W} / \mathrm{m}^{2}-\mathrm{K}$. This film coefficient was used corresponding to the maximum ID temperature boundary condition for the HL nozzle. Note that, for most accurate stress analysis, variable film coefficients depending on thermal-hydraulic boundary condition need to be selected. However, for this it is required to have appropriate experimental/computational thermal-hydraulic models, which is itself a major area of research and not our major focus. However, we used simplified temperature dependent variable film coefficients with maximum value of $18502.8 \mathrm{~W} / \mathrm{m} 2-\mathrm{K}$ (associated with $\mathrm{HL}$ maximum temperature of $324^{\circ} \mathrm{C}$ ). Based on this coefficient and the ID temperature profile of the HL and CL nozzles and RPV, the corresponding temperature-dependent film coefficients were estimated and used in the FE analysis. Whereas, the OD surfaces of the HL and CL nozzles and RPV were assumed to be perfectly insulated. For the initial condition the temperature was assumed to be approximately $41.5^{\circ} \mathrm{C}$, which is similar to the containment inside temperature. For example, according to the Westinghouse NPP manual [29], the containment air cooler system is designed to maintain the containment air temperature at or below $120^{\circ} \mathrm{F}$ (or $48.9{ }^{\circ} \mathrm{C}$ ). Time-dependent heat transfer analysis also requires determination of additional thermal material properties, such as mean coefficient of thermal expansion, thermal conductivity, diffusivity, and specific heat capacity. 
For the FE model, we used SA-508 carbon steel (or 508 low alloy steel) thermal properties and the corresponding properties were taken from EPRI report [30] and ASME code [31].

Thermal analysis for the RPV with HL and CL nozzles was performed with the ID temperature boundary condition shown in Figure 7 and with the OD surface being subjected to insulated conditions. We performed a heat transfer simulation in multiple FE steps (total 298), using automated time increments under each step. This multi-step model ensured estimation of a temperature profile at the peak temperature boundary condition without consuming much computational time, in contrast to a single-step based model with smaller fixed time increments. Under the above mentioned temperature boundary and film conditions, the estimated temperature histories across the HL thickness are shown in Figures 9 and 10. The spatial distributions of the OD and ID temperature at a typical time (approximately at 391.09 days) are shown in Figure 11. Figure 9 indicates that the maximum temperature in the OD surface of the HL is approximately $323.8^{\circ} \mathrm{C}$, which is approximately the same as the required maximum boundary condition temperature of approximately $324^{\circ} \mathrm{C}$ (refer to Figure 7). From the Figure 10 it can be found that, during load following the approximate maximum and minimum temperatures in HL are 324 and $301{ }^{\circ} \mathrm{C}$, respectively. Note that a large temperature variation across the thickness may be possible depending on the OD insulation material and the gap between RPV/nozzle and insulation. Larger temperature variation may create larger thermal-mechanical stress. A more accurate simulation of the reactor thermal profile requires modeling the reactor insulation and the gap between the insulation and OD surfaces. However, for further FE analysis, such as the thermal-mechanical stress analysis discussed in later sections, for simplicity, we used the nodal temperature distributions obtained under the ideal/perfectly insulated condition.

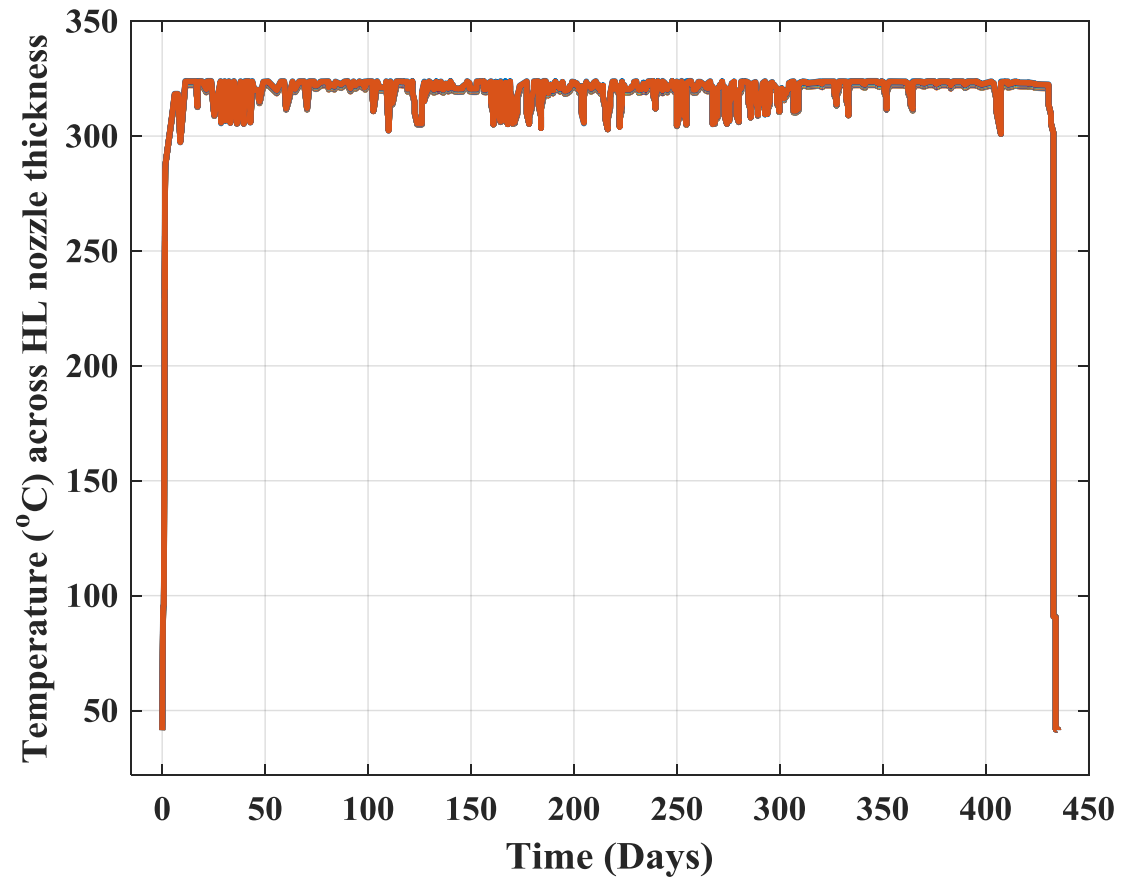

Figure 9 Temperature across HL nozzle thickness at a typical cross-section. 


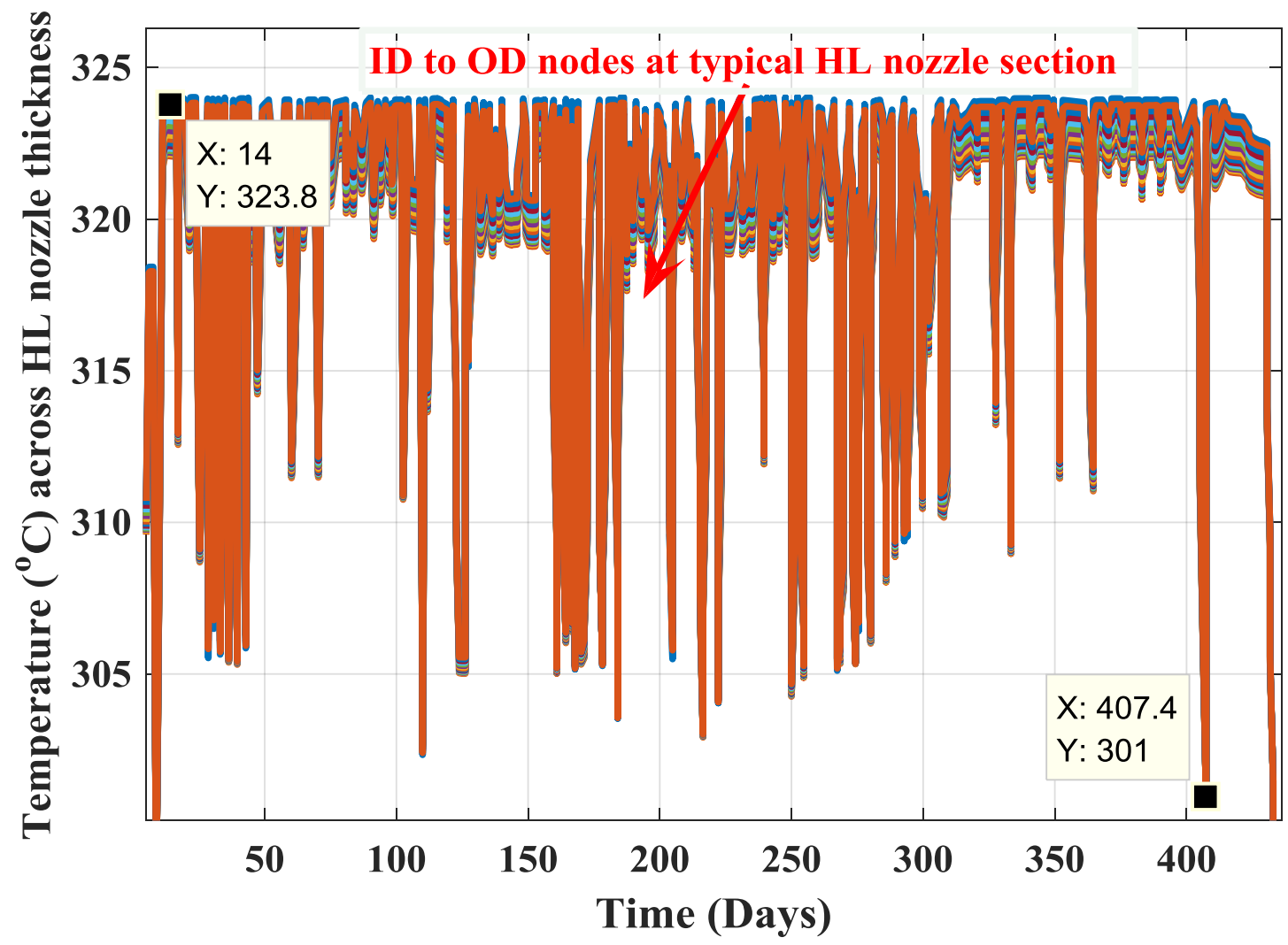

Figure 10 Magnified figure of Figure 9

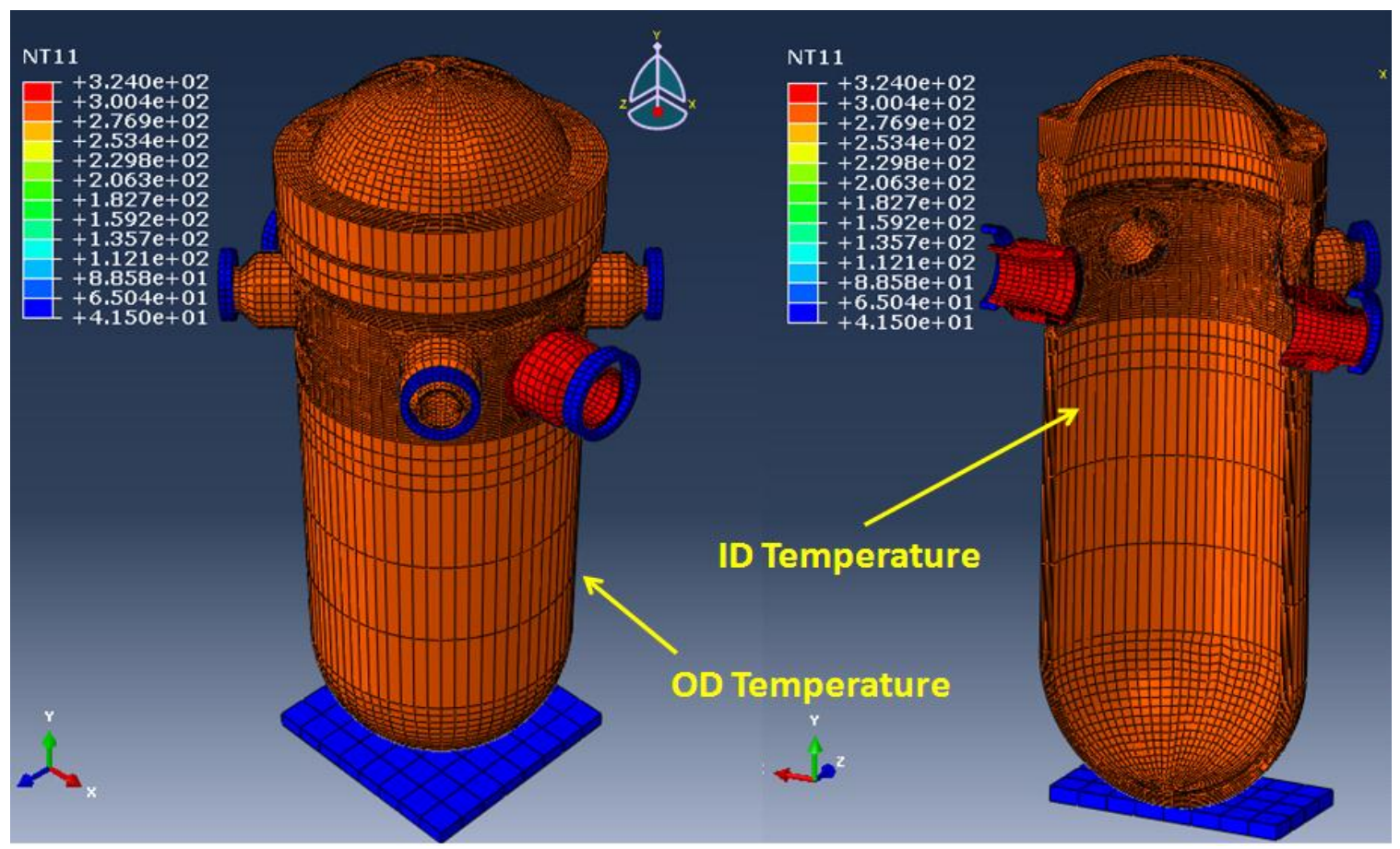

Figure 11 Spatial distribution of OD and ID temperature at approximately 391.09 days obtained through FE model. 


\section{MATERIAL PROPERTIES FOR STRUCTURAL ANALYSIS}

In our earlier work [18] we estimated the elastic-plastic material property of the 508 LAS specimen under tensile and fatigue loading (either under in-air or PWR water conditions). In the reported work we presented time-independent (based on tensile test data) and time/cycledependent (based on fatigue test data) material models using Chaboche type material models. Also the associated material parameters for 508 LAS were estimated and reported in [18]. The mentioned Chaboche kinematic hardening model has the following expression:

$$
d \alpha_{i}^{j}=\frac{2}{3} C 1_{i}^{a v} d \varepsilon{ }^{p l}-\gamma 1_{i}^{a v} \alpha_{i}^{j} \bar{p}
$$

where $\alpha_{i}^{j}$ represents the back stress, $\bar{p}$ represents the accumulated plastic strain within a cycle, and $C 1_{i}^{a v}$ and $\gamma 1_{i}^{a v}$ are the average (over upward and downward half cycle in a tension-compression fatigue test) kinematic hardening material constants that are dependent on fatigue cycle. In the discussed ABAQUS based FE models, we used some of those earlier reported material parameters directly through ABAQUS property module. Note, that although we estimated the cycle dependent material properties (in our earlier work [18]), for simplicity to avoid developing any complex user material (UMAT) subroutines, in the present work we have either used only fixed (or timeindependent) tensile test and/or fatigue test based half-life parameters. The details of the material model and parameters can be referred from [18].

In the discussed stress analysis work, we used material parameters from tensile tests: RTT06 $\left(22^{\circ} \mathrm{C}\right.$, in-air condition) and ET-T08 $\left(300^{\circ} \mathrm{C}\right.$, in-air condition) and fatigue tests: RT-F08 (22 ${ }^{\circ} \mathrm{C}$, in-air condition), ET-F24 (300 ${ }^{\circ} \mathrm{C}$, in-air condition), and EN-F20 (300 ${ }^{\circ} \mathrm{C}$, PWR condition). For easier reference, some of the important material properties are reproduced in Table 1 . The details of the material testing and property estimation procedures can be found in reference [18]. Table 1 summarizes the material properties used for the elastic-plastic stress analysis. In general, for elastic-plastic stress analysis, commercially available software such as ABAQUS requires elastic modulus $(E)$, Poisson's ratio, yield stress $\left(\sigma_{Y L}\right)$, and kinematic hardening parameters $\left(C_{1}\right.$ and $\gamma_{1}$ ) as input parameters. These parameters at temperatures of $22{ }^{\circ} \mathrm{C}$ and $300{ }^{\circ} \mathrm{C}$ (as given in Table 1) were provided as input to ABAQUS. For temperatures between $22{ }^{\circ} \mathrm{C}$ and $300{ }^{\circ} \mathrm{C}$ and beyond $300{ }^{\circ} \mathrm{C}$ (note the maximum temperature in the discussed work is $324{ }^{\circ} \mathrm{C}$ ), the material properties were linearly interpolated/extrapolated. For all temperatures, Poisson's ratio was assumed constant and equal to 0.3 . In the discussed work we used materials properties based on the $0.05 \%$ offset yield stress compared to the usual $0.2 \%$ offset yield stress. This is to capture more plastic region under the stress-strain curves. This $0.05 \%$ offset yield stress was selected based on the room temperature and $300{ }^{\circ} \mathrm{C}$ tensile test data of 508 LAS specimens. The respective stressstrain curves showing various offset yield limit are shown in Figures 12 and 13. Generally Lüders or slip bands are observed in 508 LAS at room temperature and the corresponding yield stress is selected based on the lower yield point in stress-strain curve. From Figure 12, it can be seen that $0.05 \%$ offset yield stress is a lower estimation compared to the upper yield point.

Note that, from the fatigue test data, we only used the material properties associated with the half-life of the corresponding fatigue test. In Table 1 both tensile and fatigue test based material parameters are given. The tensile test based data (e.g. yield and ultimate stress) were used for estimating critical principal stress and critical fracture energy (discussed below), whereas the fatigue test based data used for regular elastic-plastic stress analysis. Some of the additional tensile 
test based parameter (e.g. elastic modulus, Chaboche parameters) were provided to compare those value with corresponding fatigue test based parameters.

In addition to the required material properties for elastic-plastic stress analysis, we need to provide additional material properties for performing crack initiation/propagation analysis with the extended finite element method (XFEM). We performed stress analysis of the RPV with/without preexisting crack. To perform the stress analysis of a component with crack initiation/propagation modeling, ABAQUS requires damage initiation and propagation criteria depending on the chosen failure theory. In the discussed work we used criteria based on the maximum principal stress for crack initiation from a notch (in the present case, a preexisting crack mimicking a primary water stress corrosion or PWSCC crack). The crack initiation criteria are obtained from the following equation:

$$
f=\frac{\left\langle\sigma_{\max }^{p}\right\rangle}{\sigma_{c r}^{p}}=\left\{\begin{array}{l}
\geq 1+f_{\text {tol }} \quad \text { crack will initiate } \\
<1+f_{\text {tol }} \quad \text { crack willnotinitiate }
\end{array}\right.
$$

where $\sigma_{\max }^{p}$ is the solution-dependent maximum principal stress, and $\sigma_{c r}^{p}$ is the critical principal stress that has to be provided as input. In Eq. (3), the symbol \langle\rangle represents Macaulay brackets with $\left\langle\sigma_{\max }^{p}\right\rangle=0$ if $\sigma_{\max }^{p}<0$, i.e., when the maximum principal stress is purely compressive. In our work we chose the critical principal stress as

$$
\sigma_{c r}^{p}=\frac{\sigma_{Y L}+\sigma_{u}}{2}
$$

where $\sigma_{Y L}$ and $\sigma_{u}$ are the yield stress and ultimate stress corresponding to any particular temperature, respectively.

In addition to the critical principal stress, ABAQUS requires damage propagation criteria for damage evolution within an element. We used a linear energy-based criteria for which ABAQUS requires critical fracture energy. We estimated the critical fracture energy using the fracture toughness data (for 533 grade low alloy steel) given in reference [34] and elastic modulus data given in Table 1 . The critical fracture energy $G_{I C}$ can be estimated using the following relation:

$$
G_{I C}=\frac{K_{I C}^{2}}{E}
$$

where $K_{I C}$ is the fracture toughness. The estimated temperature-dependent critical fracture energy data are shown in Figure 14. Note that according to the proposed crack initiation criteria and for the considered material (508 LAS), crack will only initiate when the stress in the structure is beyond yield strength (refer Table 1). In other word, the crack will only initiate in an element when there is plastic deformation in that element. According to XFEM modeling procedure (as followed in the ABAQUS software) the crack has to propagate across the entire element at a time if the crack initiation criterion is satisfied. Once the crack propagates through an element the crack tip either has to stay at the boundary of that element or to make it totally open. If the crack tip is at the boundary of a cracked element, unless the crack initiation criteria satisfied in the element ahead of the crack tip, the crack tip remain stagnant to its original location. Also note that, the crack plane is solution-dependent and is perpendicular to the direction of the maximum principal stress. This 
allows crack propagation with changing crack plane. For estimating $\sigma_{c r}^{p}$ for the discussed stress analysis cases, we chose parameters from corresponding tensile tests (refer Table 1). The tensile tests were conducted using un-notched smooth specimen. Without unavailability of adequate crack initiation related experimental data for $508 \mathrm{LAS}$, we assume it is a good start to consider smooth specimen based tensile test data for critical principal stress estimation. Also the selected critical principal stress criteria (refer Eq. 4) is based on our earlier work [32], for which the FE model estimated data fairly matched with corresponding experimental data. Similar $\sigma_{Y L}$ and $\sigma_{u}$ dependent values of $\sigma_{c r}^{p}$ were also used by another research group [33], which had verified their XFEM-based results with corresponding experiment data. Regarding crack propagation criteria, we followed linear fracture mechanics based critical fracture energy (refer Eq. 5) assuming the crack will propagate within an element based on linear fracture mechanics based traction separation principle, which is followed in the ABAQUS to implement the XFEM capability [20].

Table 1 Material model parameters ( $0.05 \%$ offset strain stress used as yield limit stress) for 508 LAS base metal specimens at selected fatigue cycles and for tensile tests [18].

\begin{tabular}{|c|c|c|c|c|c|c|c|c|}
\hline \multicolumn{2}{|c|}{$\begin{array}{l}\text { Tensile test or fatigue test } \\
\text { cycle no. }\end{array}$} & $\begin{array}{l}\text { Env. } \\
\text { type }\end{array}$ & $\begin{array}{c}E \\
(\mathbf{G P a})\end{array}$ & $\begin{array}{c}\sigma_{Y L} \\
(\mathbf{M P a})\end{array}$ & $\begin{array}{c}\sigma_{u} \\
(\mathbf{M P a})\end{array}$ & $\begin{array}{l}\sigma_{c r}^{p} \\
(\mathrm{MPa})\end{array}$ & $\begin{array}{c}\text { Nonlin. } \\
\text { Model } C_{1} \\
(\mathrm{MPa})\end{array}$ & $\begin{array}{c}\text { Nonlin. } \\
\text { Model } \gamma_{1} \\
\text { (MPa) }\end{array}$ \\
\hline \multirow{2}{*}{\multicolumn{2}{|c|}{$\begin{array}{l}\text { Tensile tests (T06, and T08 } \\
\text { data) }\end{array}$}} & RT & 209.19 & 427.31 & 563.18 & 495.25 & 2150.4 & -13.087 \\
\hline & & ET & 197.57 & 415.15 & 610.28 & 512.71 & 10699 & 49.624 \\
\hline \multirow{4}{*}{$\begin{array}{c}\text { Selected } \\
\text { fatigue } \\
\text { cycles } \\
\text { (RT-F23, } \\
\text { ET-F24, } \\
\text { and } \\
\text { EN-F20) }\end{array}$} & $\mathrm{Cy}=1$ & EN & 184.51 & 391.55 & - & - & 61236 & 666.75 \\
\hline & \multirow{3}{*}{$\begin{array}{c}\mathrm{Cy}=\mathrm{N} / 2 \text { for } \\
\mathrm{RT}-\mathrm{F} 23= \\
2247, \\
\text { ET-F24= } \\
1375 \text {, and } \\
\text { F20 }=1438\end{array}$} & RT & 196.25 & 338.37 & - & - & 59082 & 537.76 \\
\hline & & ET & 201.61 & 416.82 & - & - & 71618 & 809.75 \\
\hline & & $\mathrm{EN}$ & 190.18 & 432.1 & - & - & 72998 & 675.49 \\
\hline
\end{tabular}

* RT, ET, and EN symbolize room temperature, elevated temperature, and PWR environment, respectively. 


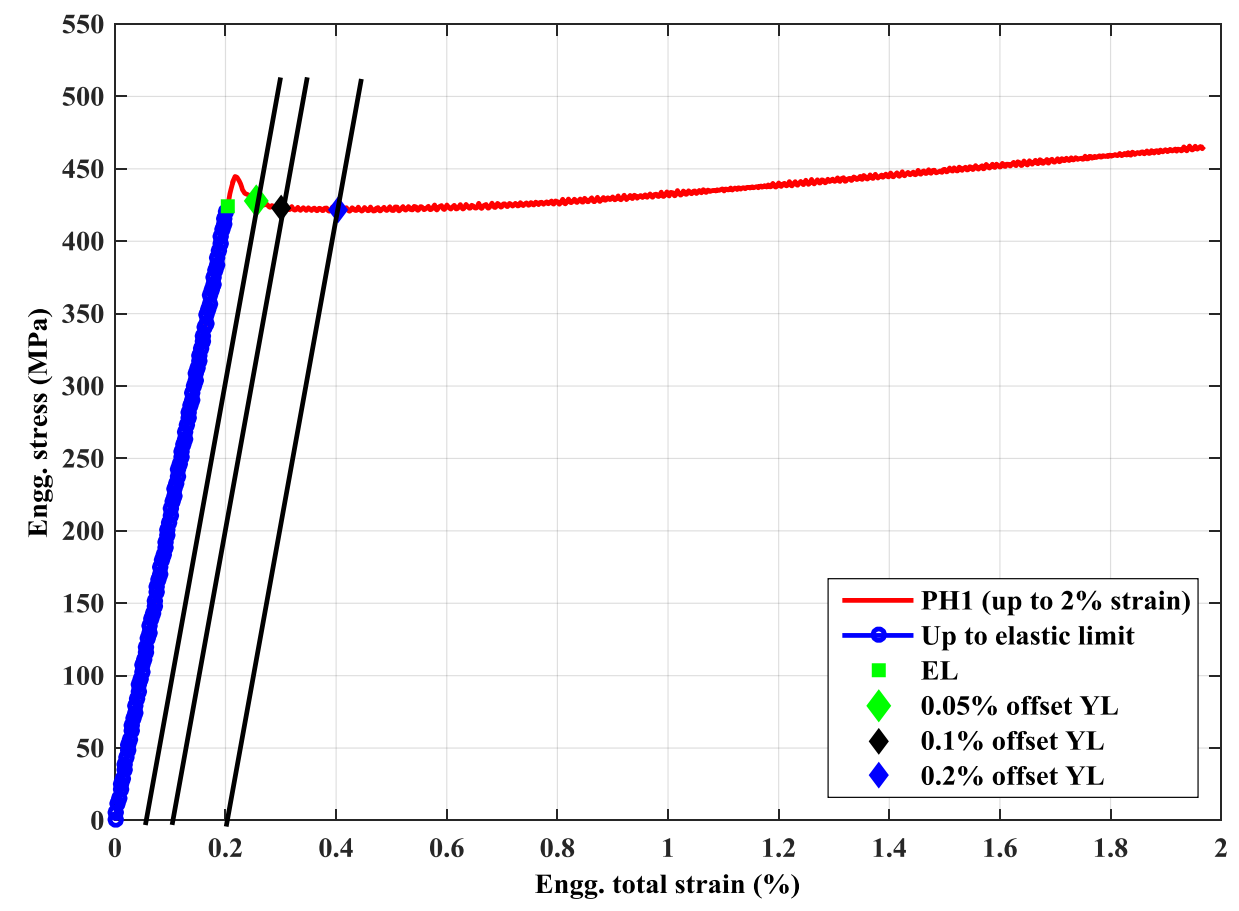

Figure 12 Engineering stress-strain curve (up to $2 \%$ strain) estimated from T06 (room temperature) tensile test data showing assumed elastic limit (EL) and estimated various offset yield limits (YL)

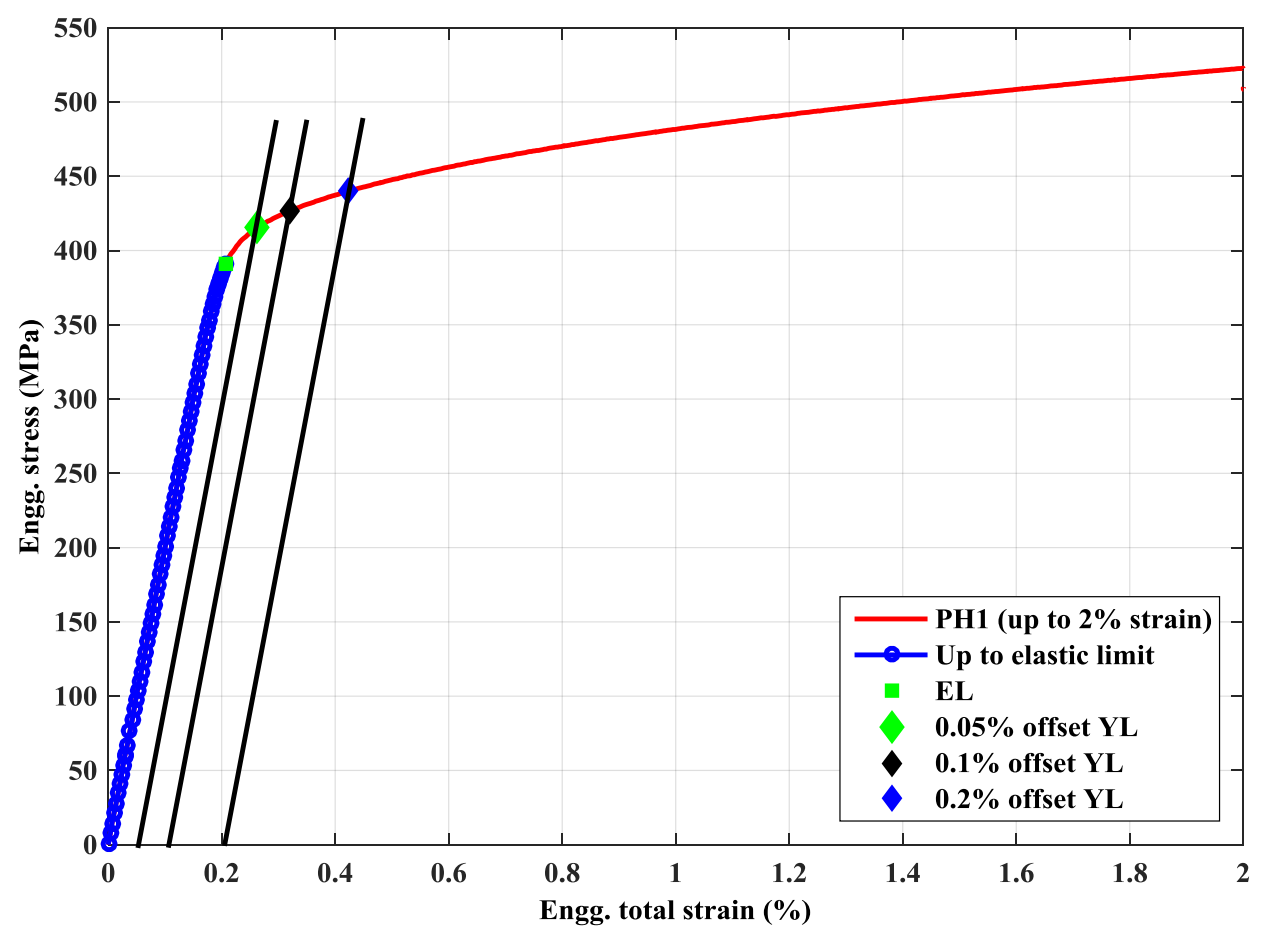

Figure 13 Engineering stress-strain curve (up to $2 \%$ strain) estimated from T08 $\left(300{ }^{\circ} \mathrm{C}\right.$ ) tensile test data showing assumed elastic limit (EL) and estimated various offset yield limit (YL) 


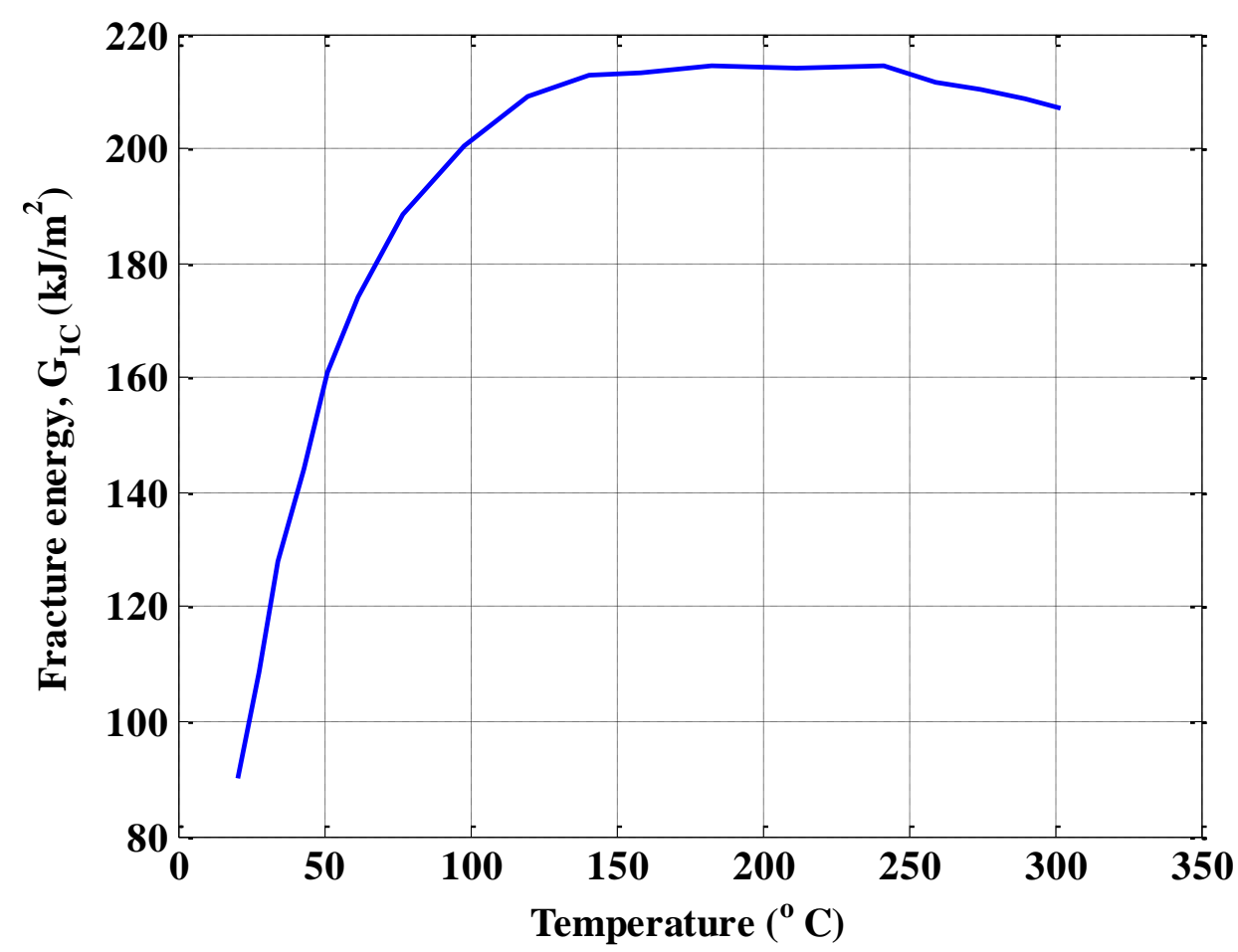

Figure 14 Estimated critical fracture energy for 533 LAS and used in the XFEM-based simulation.

\section{THERMAL-MECHANICAL STRESS ANALYSIS OF RPV AND NOZZLES WITHOUT PREEXISTING CRACKS}

We performed thermal-mechanical stress analysis using the RPV FE model discussed above. Nodal temperatures from the heat transfer analysis discussed earlier were used as input. In addition to the nodal temperature input, we modeled the internal coolant water pressure. The timedependent pressure history shown in Figure 8 was used as the ID surface pressure boundary for the RPV, HL, and CL nozzles. For the nozzles we assumed they had no preexisting cracks and had been subjected to the same pressure boundary conditions. Sequentially coupled thermalmechanical stress analyses were conducted with predetermined temperature data from thermal analysis. Two simulations were performed with different sets of material properties to study the effect of in-air versus PWR conditions. Both simulations were conducted using the half-life (cycle $=\mathrm{N} / 2$, where $\mathrm{N}$ is the total fatigue life) material properties given in Table 1. The two simulation conditions are:

- Case 1 (in-air condition): Elastic-plastic material properties were interpolated/extrapolated using the elastic-plastic material properties estimated from half-life (cycle $=\mathrm{N} / 2)$ stressstrain data of RT-F23 (in-air, $22^{\circ} \mathrm{C}$ ) and ET-F24 (in-air, $300^{\circ} \mathrm{C}$ ) tests.

- Case 2 (PWR water condition): Elastic-plastic material properties were interpolated/extrapolated using the elastic-plastic material properties estimated from halflife (cycle=N/2) stress-strain data of RT-F23 (in-air, $22^{\circ} \mathrm{C}$ ) and EN-F20 (PWR water, 300 
$\left.{ }^{\circ} \mathrm{C}\right)$ tests. We assumed at room temperature there is no environmental effect on material properties.

Figure 15 shows a comparison between case 1 and case 2 of thermal strain at maximum stressed location (refer Figure 21) for the H L nozzle. Figure 16 shows the magnified version of Figure 15. In addition to thermal strain, we estimated the histories of total strain and Von-Mises stress at the above-mentioned maximum stress locations. Figure 17 shows the total strain histories for the HL nozzle, obtained from the case- 1 and case- 2 FE models. Figures 18 shows the magnified version of Figure 17. From Figure 18 it can be seen that between the two cases the PWR condition based FE model estimates approximately $0.01 \%$ higher strain. Figure 19 shows the corresponding comparison of the Von-Mises stress for the HL nozzle. Figure 20 show the magnified version of Figure 19. Furthermore, Figure 21 shows the example temperature versus Von-Mises stress profile near the nozzle area (at different instances during heat-up and full power) obtained through the case-1 FE simulation (in-air condition). Through the above shown example results, we would like to mention that the stress analysis results may vary depending on whether the material properties estimated from in-air condition or PWR water condition fatigue tests. Furthermore, in the discussed work we performed FE simulation considering material properties estimated from halflife stress-strain data. There may be substantial variation in stress-strain results, if cyclic or timedependent effect of material properties considered. However, in the present work, this is not our major focus.

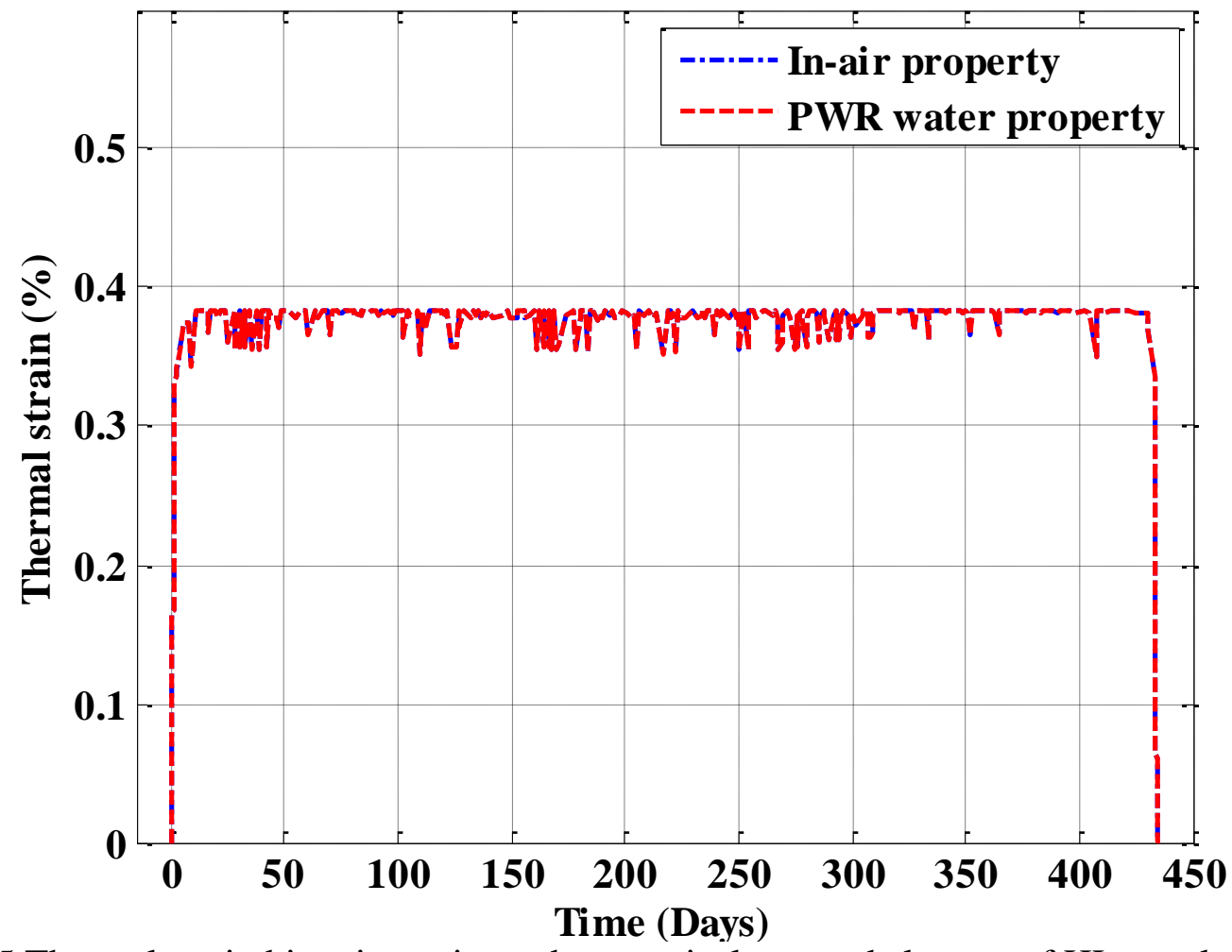

Figure 15 Thermal strain histories estimated at a typical stressed element of HL nozzle for in-air and PWR water conditions. 


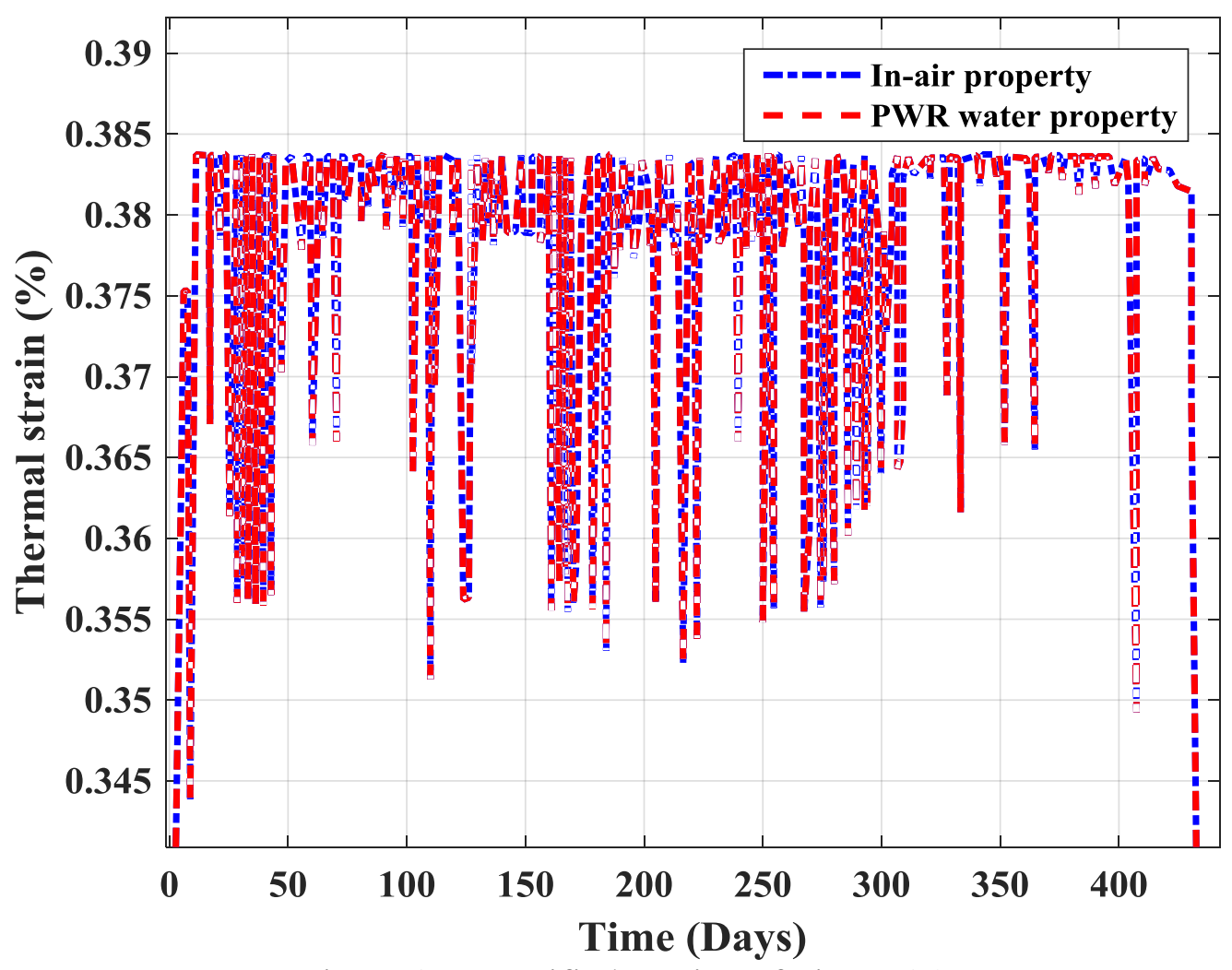

Figure 16 Magnified version of Figure 15.

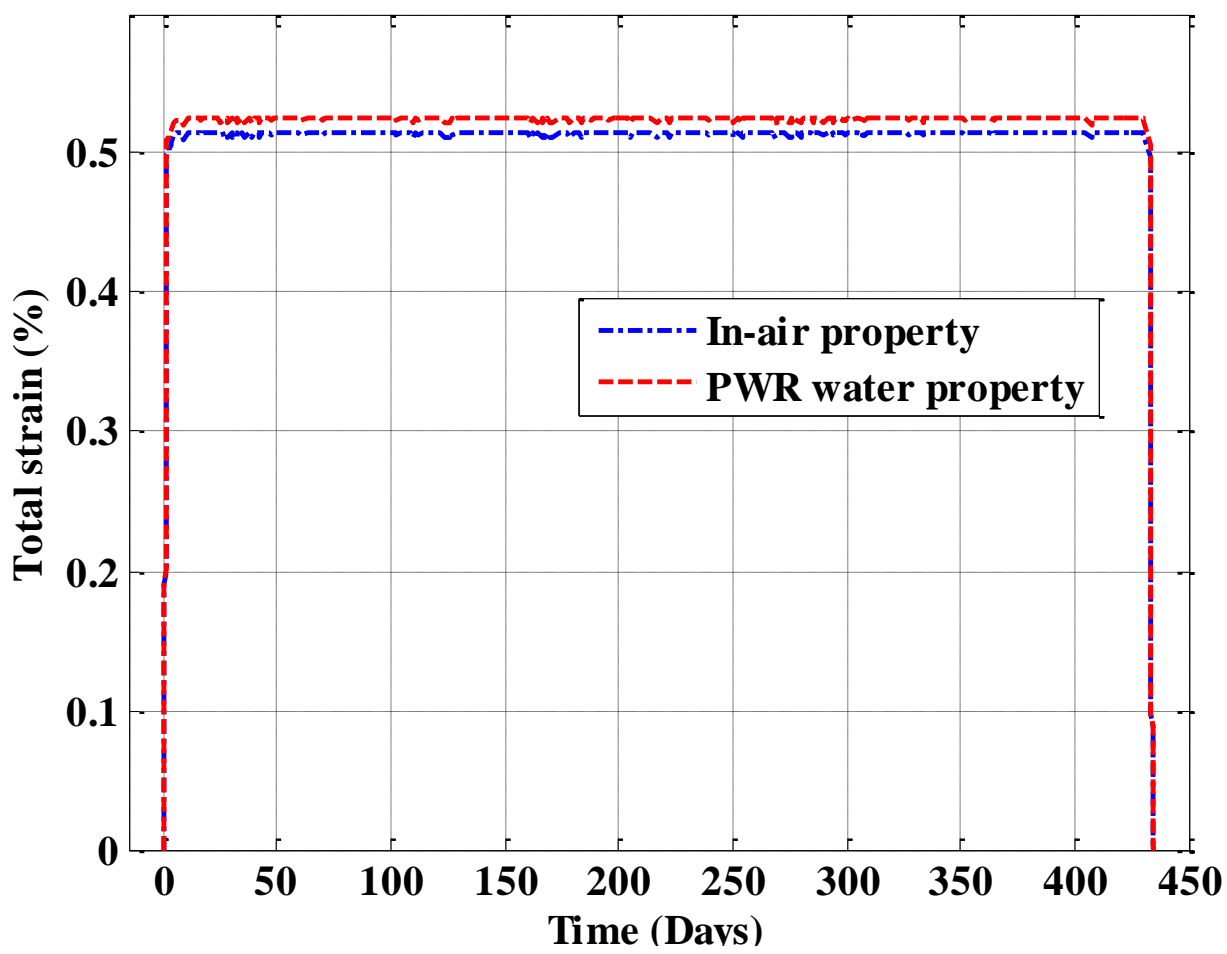

Figure 17 Total strain histories estimated at a typical stressed element of HL nozzle for in-air and PWR water conditions. 


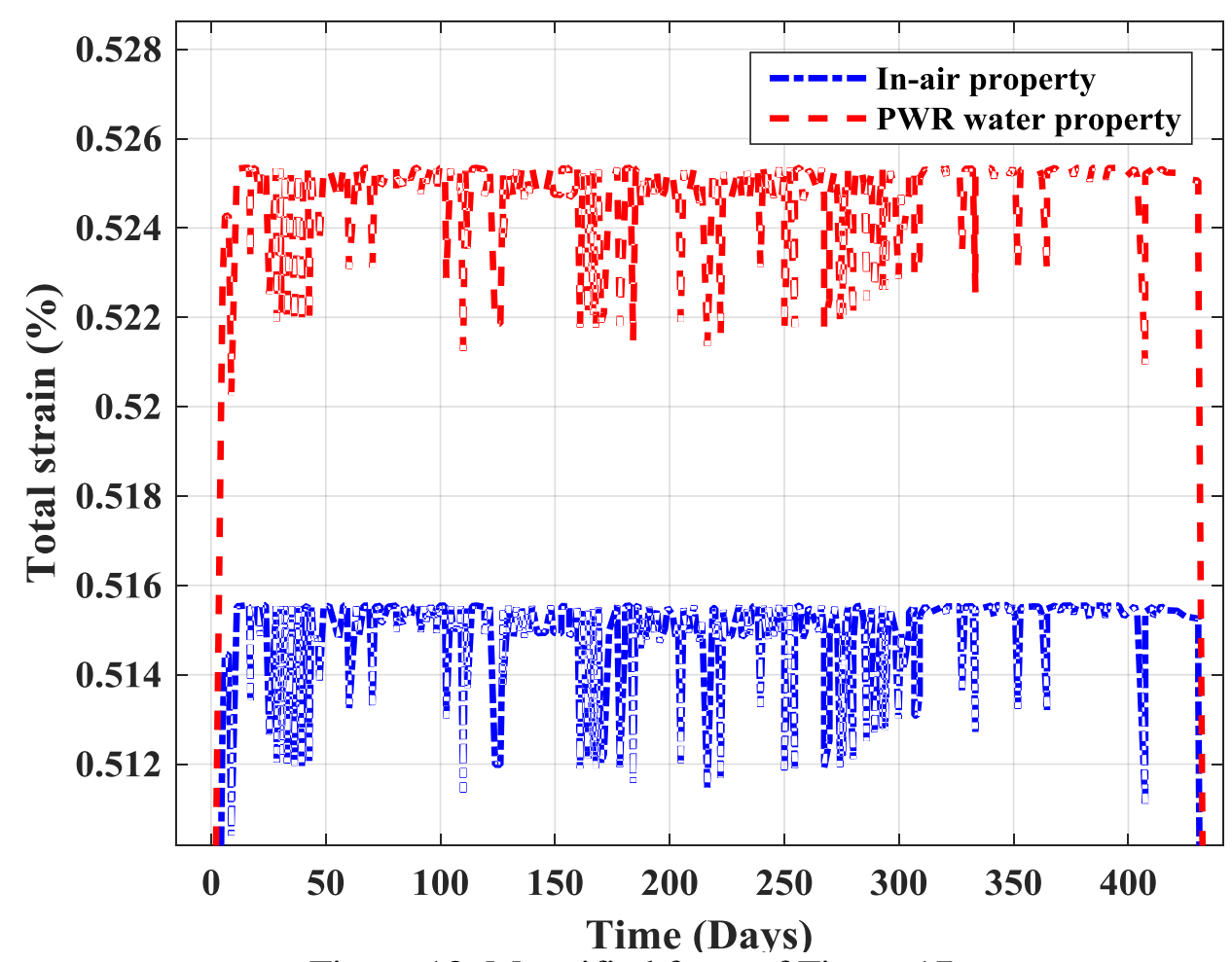

Figure 18 Magnified form of Figure 17.

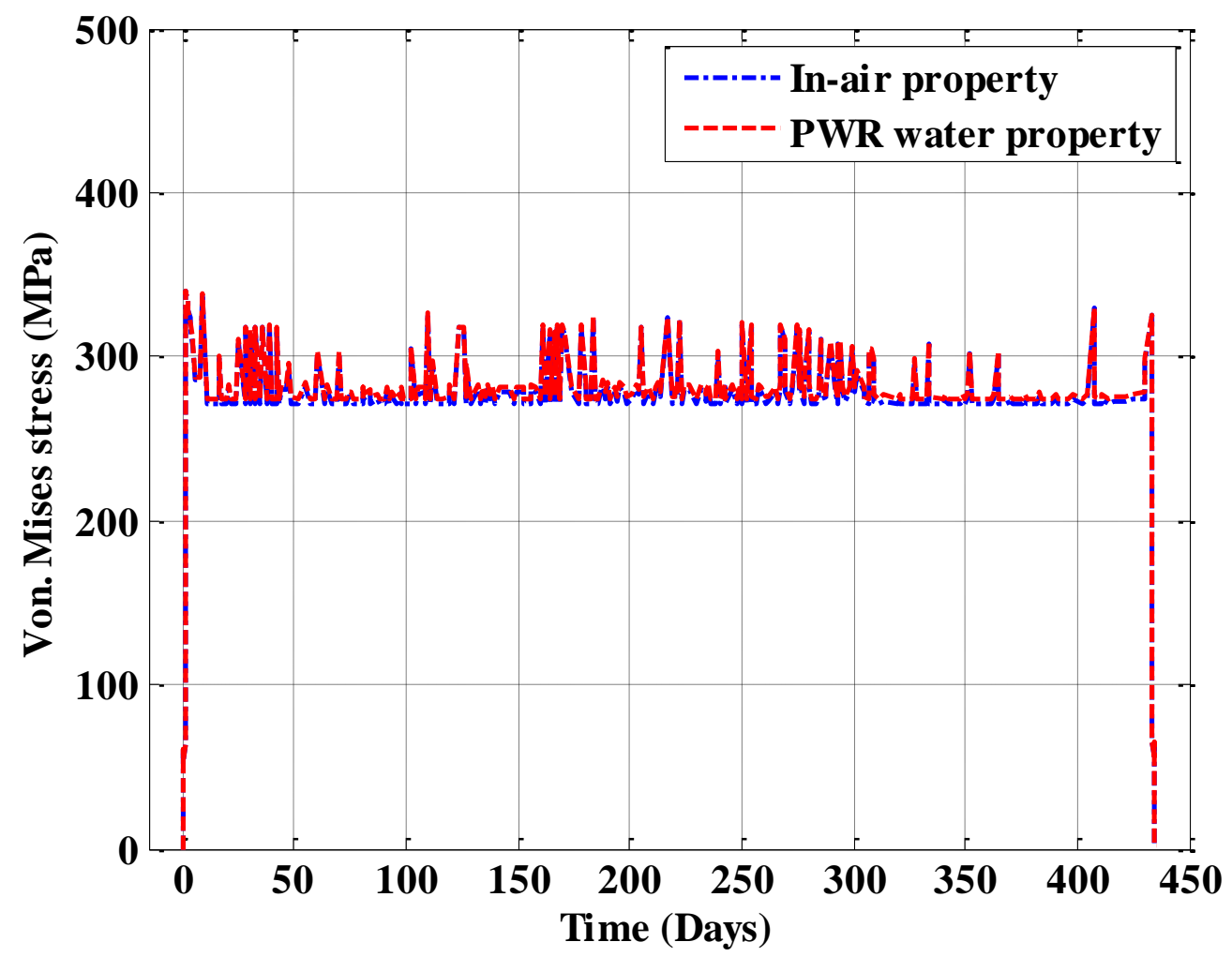

Figure 19 Von-Mises stress histories estimated at a typical stressed element of HL nozzle for inair and PWR water conditions. 


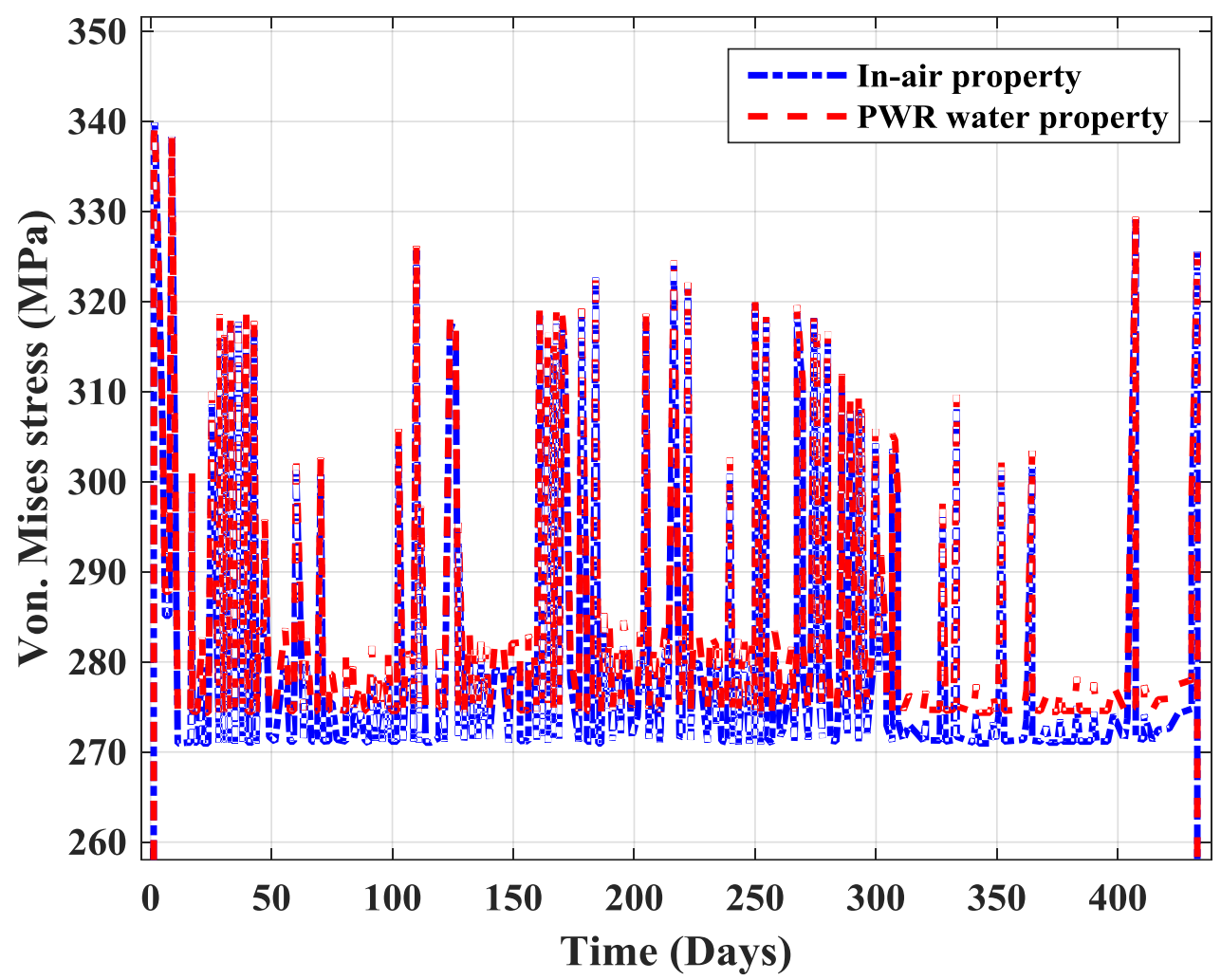

Figure 20 Magnified form of Figure 19. 


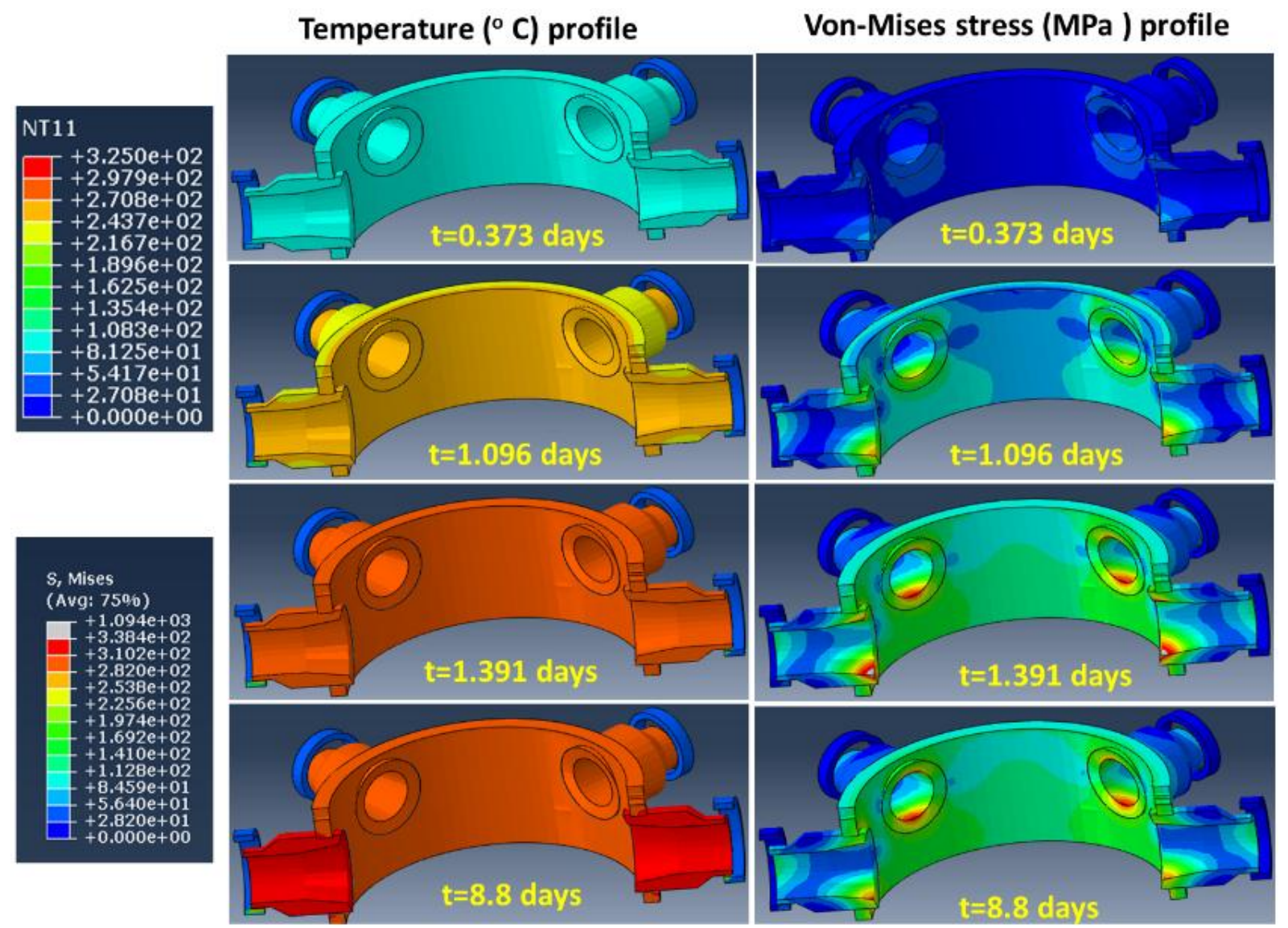

Figure 21 Example temperature versus Von-Mises stress profile near the nozzle area (at different instances during heat-up and full power) obtained through case-1 FE simulation (in-air condition).

\section{EFFECT OF END CAP LOAD ON STRESS ANALYSIS RESULTS}

The effect of end cap loads invoked from connected piping systems and internal pressure can affect the stress analysis results. To check the effect of end cap loads, the above discussed FE model (case 2 with PWR water property) was simulated with end cap load. The time-varying end cap load applied as distributed pressure load $\sigma_{c a p}(t)$ on end section of the HL and CL nozzle. The expression of the end cap pressure can be given as:

$$
\sigma_{c a p}(t)=\frac{R_{i}^{2}}{R_{o}^{2}-R_{i}^{2}} P(t)=F_{c a p} P(t)
$$

Where $\mathrm{P}(\mathrm{t})$ is the time varying internal pressure in HL and CL pipes, $R_{o}$ and $R_{i}$ are respectively the outer and inner radius of HL and CL pipes. Also in Eq. (5) $F_{c a p}=\frac{R_{i}^{2}}{R_{o}^{2}-R_{i}^{2}}$ is a factor based on the inner and outer radius of HL and CL pipe. With $R_{o}=344.42 \mathrm{~mm}$ and $R_{i}=279.4 \mathrm{~mm}$ for CL pipe and $R_{o}=476.25 \mathrm{~mm}$ and $R_{i}=393.7 \mathrm{~mm}$ for HL pipe, the respective end cap load factor $F_{c a p}$ are estimated as 1.9246 and 2.1583. Figure 22 shows the example Von-Mises stress histories at a typical stressed element of left HL nozzle, estimated from the FE models without and with 
considering cap load. Figure 23 shows the corresponding magnified form of Figure 22. From Figure 22 and 23 it can be seen that there is not much effect due to the end cap load. This is possibly due to the dependence of end cap load on internal pressure, which has no significant contribution on overall stress state in RPV and nozzles compared to the contribution from thermal load. This can be evident by comparing the thermal strain histories (Figure 15) with total strain histories (Figure 17). However, for completeness in the onward discussed results the effect of end cap load is considered.

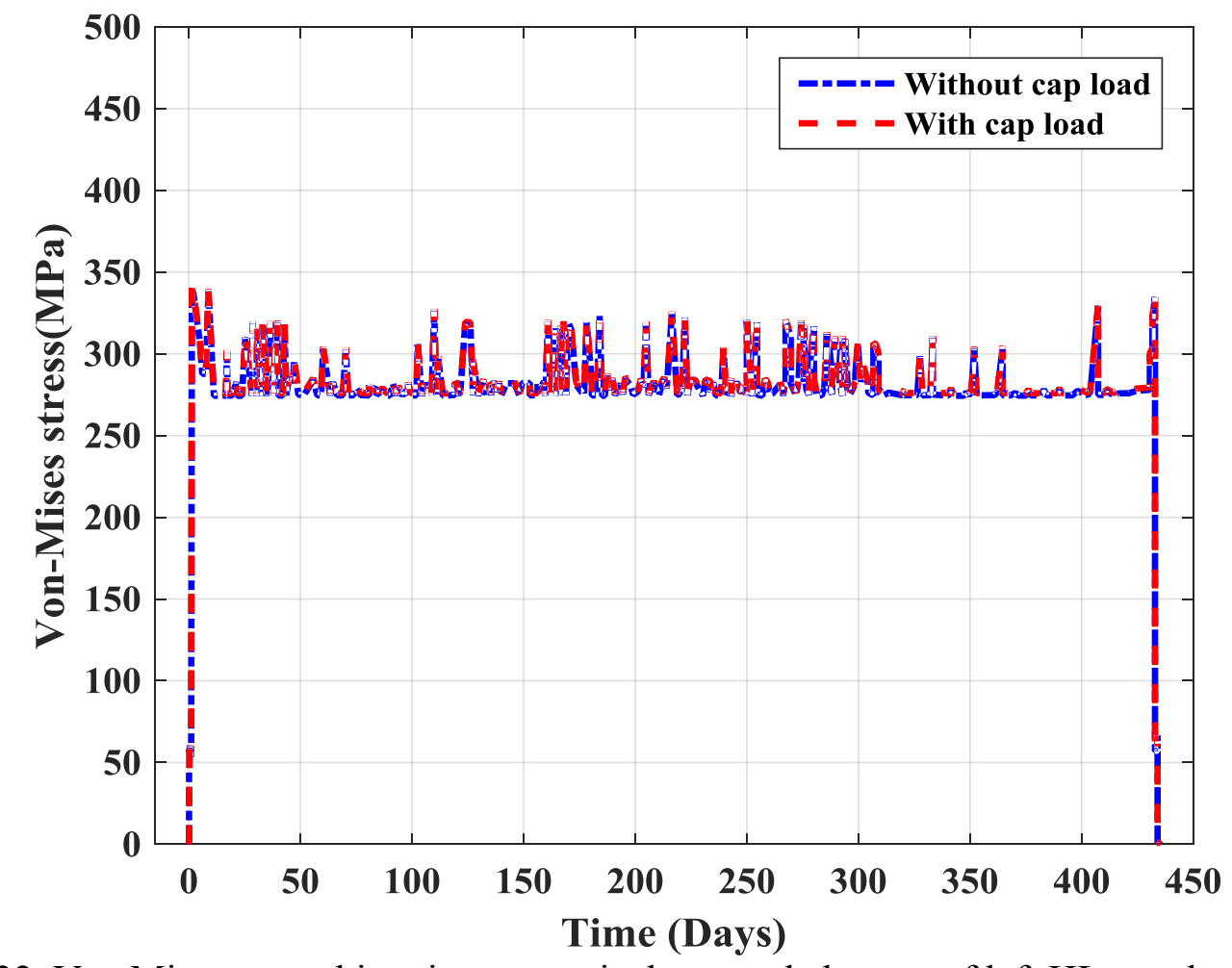

Figure 22 Von-Mises stress histories at a typical stressed element of left HL nozzle estimated from FE models without and with considering cap load. 


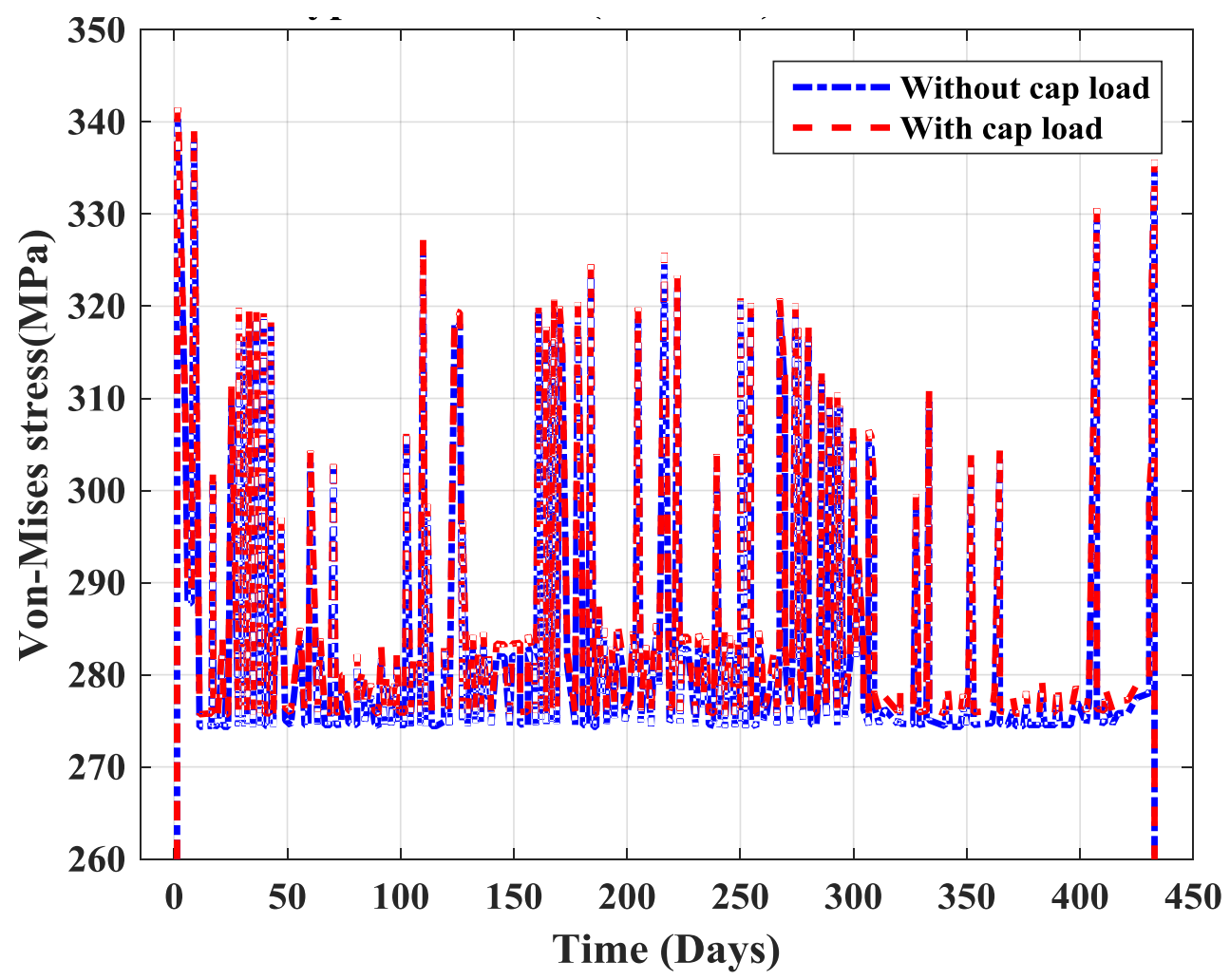

Figure 23 Magnified form of Figure 22.

\section{XFEM MODELING AND THERMAL-MECHANICAL STRESS ANALYSIS OF RPV AND NOZZLES WITH PREEXISTING CRACKS}

A crack could develop in reactor components due to stress corrosion cracking or other environmental factors [35]. For example in October 2000, during containment inspection after entering a refueling outage at V.C. Summer NPP, an axial through-wall crack along with a small circumferential crack was found in the first weld between the reactor vessel nozzle and the hot leg piping of the coolant system (RCS) [35]. The crack was approximately 3 feet from the reactor vessel. Based on Ultrasonic testing data, it was found that the axial crack initiated from the ID surface and became complete through-wall. Primary water stress corrosion cracking (PWSCC) was suspected to be the main mechanism behind this type of crack formation. In general, rector components are designed to restrict their stress state within the elastic limit. However, fatigue crack often found in reactor components (as in case of V.C. Summer NPP), due to presence of plastic zone and its interaction with reactor environment. The plastic zone can be generated due to presence of residual stress and/or due to presence of crack/notch. In a reactor nozzle, the residual stress associated with weld are the major reason of crack initiation. Once the crack initiated, the crack can further grow due to the presence of plastic zone associated with initiated crack and due to its exposure to reactor coolant environment. In the discussed work we have considered a simulated preexisting (part-through-wall axial crack) crack in HL nozzle of RPV. This is to mimic a preexisting PWSCC crack. The purpose of the discussed work, is not necessarily to simulate the exact V.C Summer type cracked nozzle condition, but to check the effect of a pre-existing crack in stress analysis results, particularly under grid-load-following condition. In addition, we wanted to see if there is any presence of plastic zone and its growth due to the presence of crack. Note that, 
for simplicity we have not modeled the weld residual stress in the discussed FE model. Rather, we only modeled the pre-existing crack/notch to check its effect on stress analysis results and plastic zone growth. However, for more accurate stress analysis results, it is necessary to model the effect of residual stress associated with nozzle welds. This is one of our future work.

Figure 24 shows the shape, approximate size and location of the crack in the left HL nozzle of RPV. A thermal-mechanical stress analyses under the grid load-following condition were performed to predict the stress-strain state of the RPV. The FE simulation was performed using elastic-plastic material properties interpolated/extrapolated by using the elastic-plastic material properties estimated from half-life (cycle $=\mathrm{N} / 2$ ) stress-strain data of RT-F23 (in-air, $22^{\circ} \mathrm{C}$ ) and EN-F20 (PWR water, $300{ }^{\circ} \mathrm{C}$ ) tests. As discussed in the previous section on stress analysis models, for the FE model discussed in this section we used nodal temperature data from earlier heat transfer results.

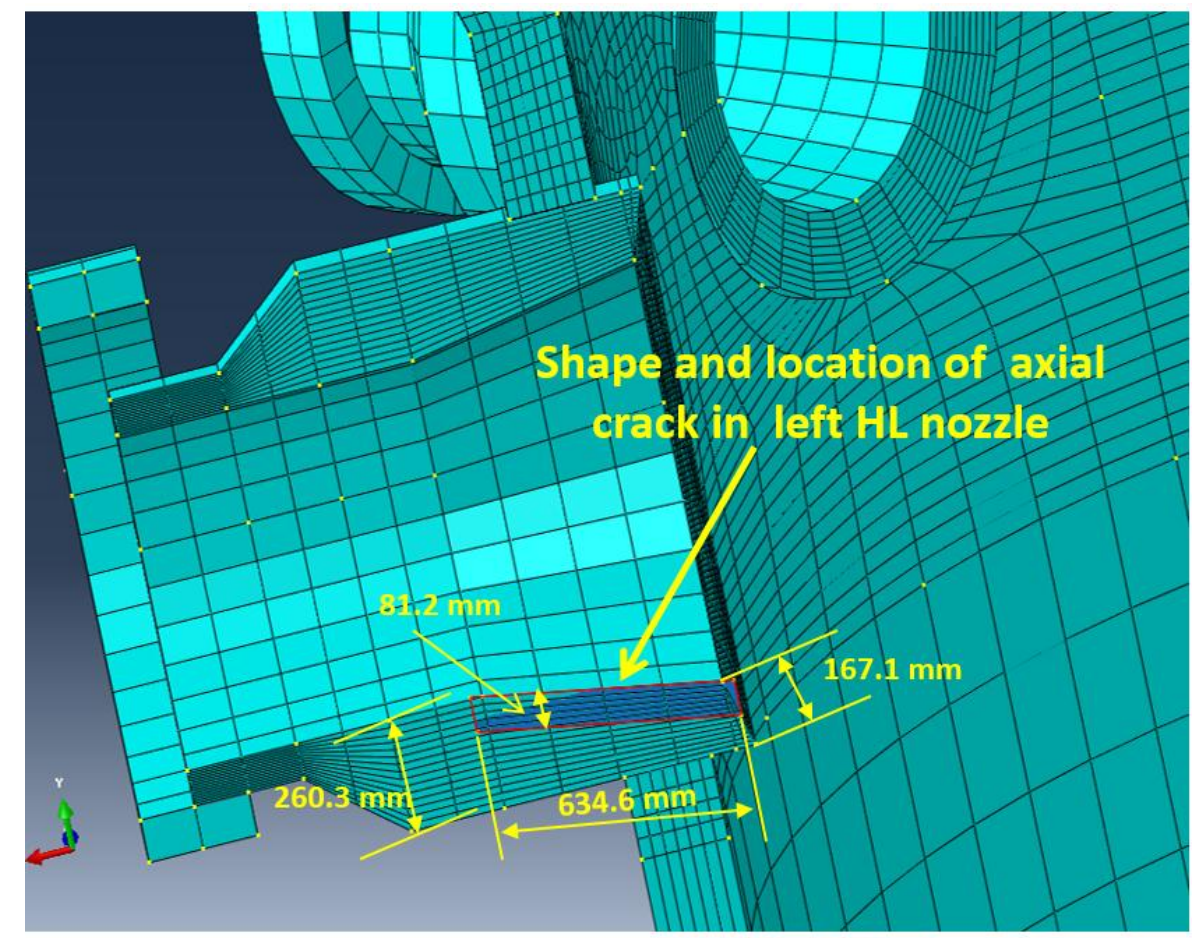

Figure 24 Shape, approximate size and location of simulated axial crack in left HL nozzle of RPV.

In addition to the nodal temperature as input, we modeled internal coolant water pressure using the time-dependent pressure boundary condition shown in Figure 8. The corresponding thermal-mechanical stress analysis results are presented here. For example, Figure 25 shows the comparison of Von-Mises stress histories (at same node in left HL nozzle), estimated from the FE models without and with considering the presence of an axial crack (in left HL nozzle). Also this figure shows stress levels at local stress concentration region (at a typical FE node) and not necessarily affect the overall structural integrity of nozzle unless the associated plastic zone (shown in Figure 27) grows over multiple fuel cycles due to combination of load cycling and interaction of plastic zone with reactor coolant environment. 
Figure 26 shows the Von-Mises stress contour at a typical full power condition (at time $=$ 421.6 days). Figure 25 indicates that the presence of a crack could create larger stress compared to the condition with no crack. Higher stress/strain could further accelerate PWSCC. Particularly higher strain can lead to accumulation of plastic strain, which can help the growth of PWSCC. We have also plotted accumulated plastic strain at different instance of heat-up and cool-down procedures. The corresponding contour plots are shown in Figure 27. From this figure it can be seen that, due to presence of crack, itself during the heat-up process plastic strain was generated. For example at $\mathrm{t}=1.391$ days (corresponding RCS heat-up temperature approximately $300{ }^{\circ} \mathrm{C}$; refer Figure 21) the accumulated plastic strain magnitude is approximately $0.047 \%$. Furthermore, Figure 27 indicates over a single reactor loading/fuel cycle (434.9 days) the plastic strain has grown to a magnitude of $0.076 \%$. The generation of plastic strain can led to cycle of plastic strain accumulation and resulting accelerated PWSCC crack growth. This could be why a through-all axial crack was formed in the V.C. Summer NPP (as mentioned above) possibly by cumulative growth of PWSCC along the axial direction. Note that in the discussed work although we have used crack initiation and propagation criteria (refer Eq. 3, 4 and 5), the FE result doesn't show any further crack initiation and propagation from the preexisting notch/crack. This is due to inadequate stress state at the notch region. Also note that, the simulation was conducted for one fuel cycle. The crack may initiate and propagate over multiple fuel cycles due to increasing plastic strain (as shown in Figure 27 for one fuel cycle). However, due to inadequate computational resource we haven't executed the FE simulation for multiple fuel cycles.

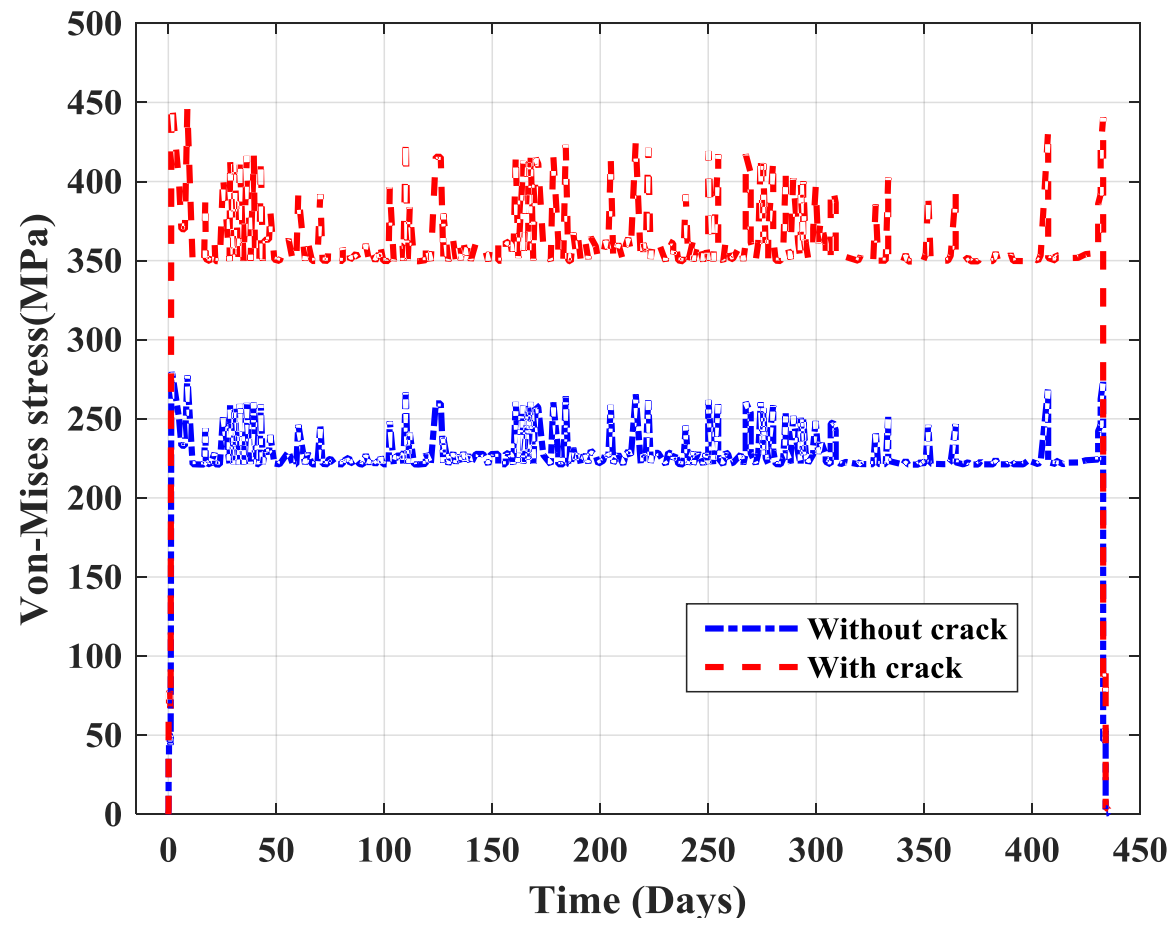

Figure 25 Comparison of Von-Mises stress histories (at same node in left HL nozzle), estimated from the FE models without and with considering the presence of an axial crack (in left HL nozzle). 


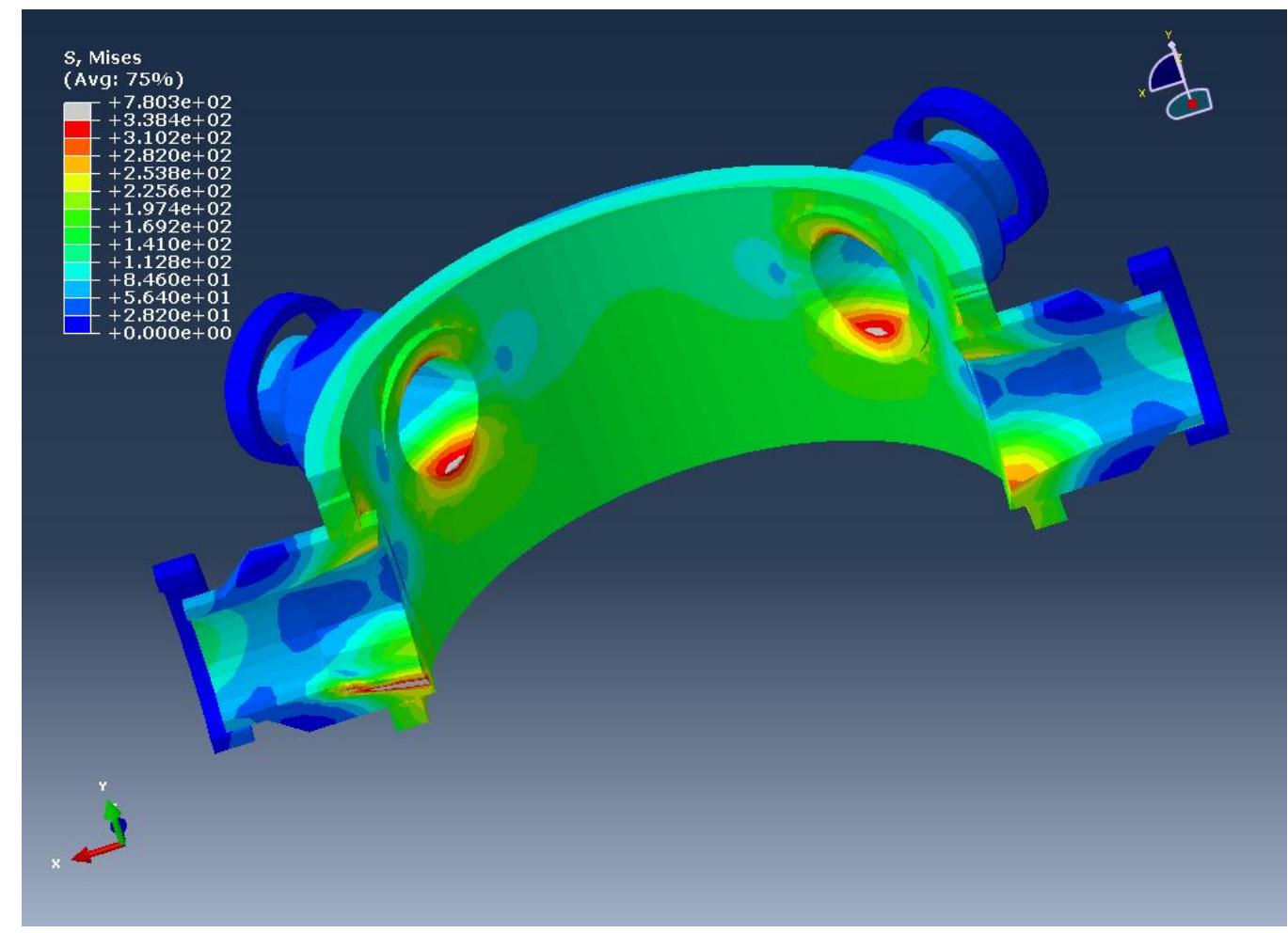

Figure 26 Von-Mises stress contour at a typical full power condition (at time $=421.6$ days).

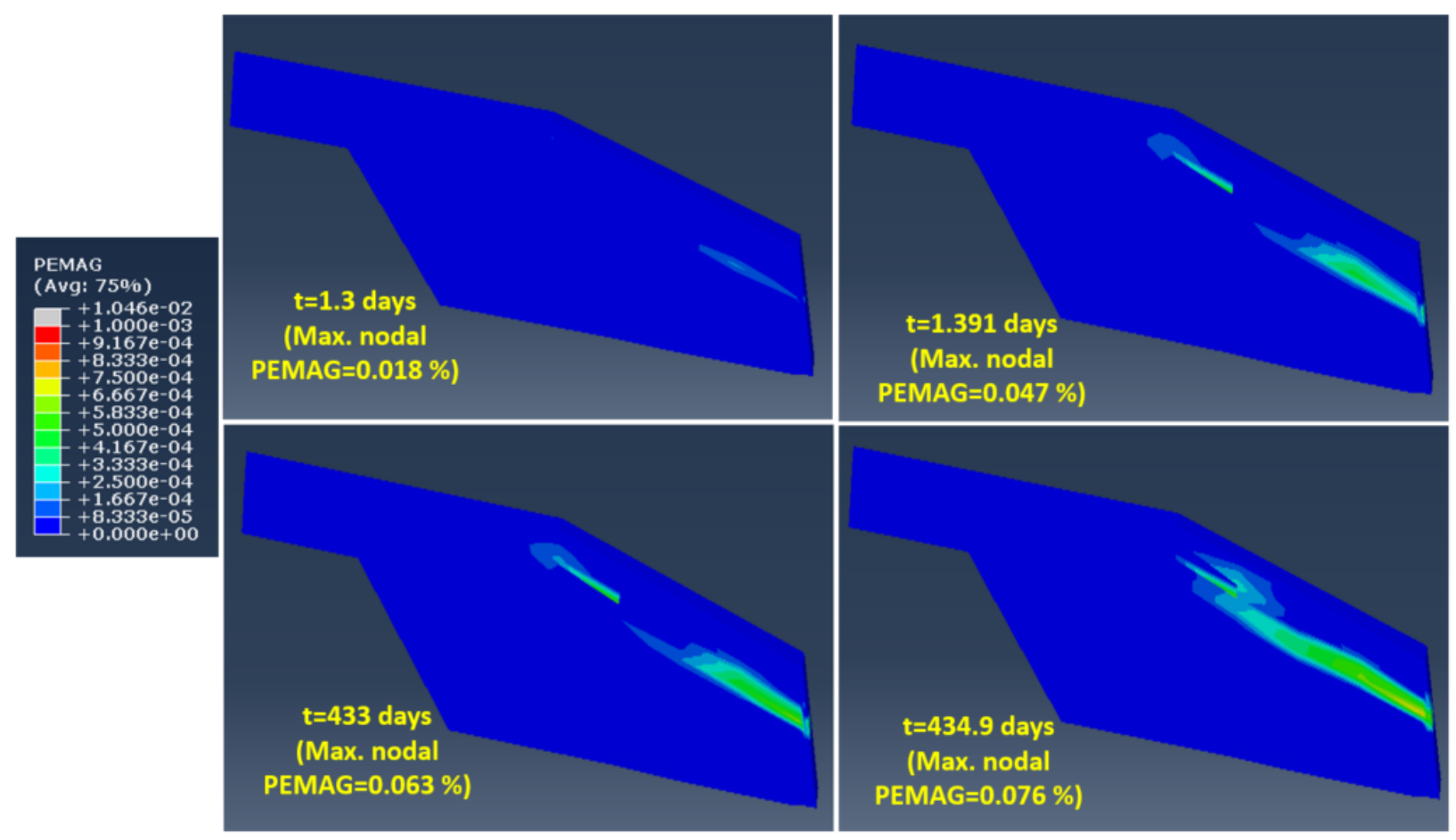

Figure 27 Contour plots of accumulated plastic strain magnitude (PEMAG) in the cracked region of HL (right hand side of contours are towards the RPV ID surface). 


\section{SUMMARY}

This paper presents results from heat transfer analysis of the RPV and its HL and CL nozzles under heat-up, cool-down, and grid load-following power operation. In addition, results from thermal-mechanical stress analysis of the RPV and nozzles with/without preexisting crack are also presented. From the thermal-mechanical stress analysis of RPV and its nozzle we found that under grid load following condition there is a variation in stress and strain states in RPV components (such as in HL nozzle) observed. The stress variation in HL nozzle even further amplified if there is a preexisting crack. From this preliminary FE model results it is found that, within a single loading/fuel cycle the plastic strain grows due to the presence of crack and stressstrain variations associated with grid load following. The cycle of plastic strain accumulation can lead to accelerated PWSCC.

\section{ACKNOWLEDGMENTS}

This research was funded by the U.S. Department of Energy's Light Water Reactor Sustainability program under the work package of environmental fatigue study, program manager Dr. Keith Leonard. 


\section{REFERENCES}

1) Chu, S., and A. Majumdar. "Opportunities and challenges for a sustainable energy future." Nature 488, no. 7411 (2012): 294-303.

2) Lokhov, A. "Load-following with nuclear power plants." NEA News 29, no. 2 (2011): 18 (https://www.oecd-nea.org/nea-news/2011/29-2/nea-news-29-2-load-following-e.pdf).

3) Lokhov, A. Technical and Economic Aspects of Load Following with Nuclear Power Plants: Nuclear Development Division. OECD Nuclear Energy Agency, Paris, France (2011).

4) Bruynooghe, C., A. Eriksson, and G. Fulli G. Load-following Operating Mode at Nuclear Power Plants (NPPs) and Incidence on Operation and Maintenance (O\&M) Costs: Compatibility with Wind Power Variability. EUR 24583 EN, Joint Research Centre, Institute for Energy, Petten, the Netherlands (2010).

5) International Atomic Energy Agency. "Load following EDF experience feedback." IAEA Technical Meeting: Load Following, https://www.iaea.org/NuclearPower/Downloadable/Meetings/2013/2013-09-04-09-06-TMNPE/8.feutry_france.pdf, Paris, France, September 4-6, (2013).

6) Savolainen, Aleksi. "The role of nuclear and other conventional power plants in the flexible energy system.", Master's thesis, Lappeenranta University of Technology,

http://www.doria.fi/bitstream/handle/10024/118575/Masters_thesis_Aleksi_Savolainen.pdf? sequence=2 (2015).

7) Ablay, Günyaz. "A modeling and control approach to advanced nuclear power plants with gas turbines." Energy Conversion and Management 76 (2013): 899-909.

8) Foley, A. M., B.P. Ó. Gallachóir, J. Hur, R. Baldick, and E. J. McKeogh. "A strategic review of electricity systems models." Energy 35, no. 12 (2010): 4522-4530.

9) Jaleeli, N., L. S. VanSlyck, D. N. Ewart, L. H. Fink, and A. G. Hoffmann, "Financial analysis of hydro-power load following and improvement of system operational flexibility through wind farm participation in AG."

https://www.bpa.gov/Doing\%20Business/TechnologyInnovation/ConferencesReservoirSyst emModeling/7_1_Antonishen.pdf.

10) Ingersoll, D.T., C. Colbert, Z. Houghton, R. Snuggerud, J. W. Gaston, and M. Empey. "Can nuclear power and renewables be friends?" Proceedings of ICAPP 2015, Paper 15555, Nice, France, May 3-6, 2015Paper 15555

(http://www.nuscalepower.com/images/our_technology/NuScale-Integration-withRenewables_ICAPP15.pdf).

11) Mohanty, S., W. Soppet, S. Majumdar, and K. Natesan. System-Level Heat Transfer Analysis, Thermal-Mechanical Cyclic Stress Analysis, and Environmental Fatigue Modeling of a Two-Loop Pressurized Water Reactor. A Preliminary Study. Argonne National Laboratory Report ANL/LWRS-15/01 (2015) (doi:10.2172/1179020, http://www.osti.gov/scitech/servlets/purl/1179020).

12) Mohanty, S., W. K. Soppet, S. Majumdar, and K. Natesan. "Full-scale 3-D finite element modeling of a two-loop pressurized water reactor for heat transfer, thermal-mechanical cyclic stress analysis, and environmental fatigue life estimation." Nuclear Engineering and Design 295 (2015): 374-387.

13) Wilhelm, P., J. Rudolph, and P. Steinmann. "Study on fatigue analysis for operational load histories." 39th MPA-Seminar, 
http://www.iaea.org/inis/collection/NCLCollectionStore/_Public/45/107/45107459.pdf (October 2013), Stuttgart.

14) Bergholz, S., J. Rudolph, F. Bruckmueller, B. Heinz, and B. Jouan. "Automatic fatigue monitoring based on real loads: Live demonstration." $38^{\text {th }}$ MPA Demonstration, Stuttgart, Germany, October 1-2, 2012

(http://www.iaea.org/inis/collection/NCLCollectionStore/_Public/46/001/46001472.pdf).

15) Rudolph, J., and S. Bergholz. "The AREVA integrated and sustainable concept of fatigue design, monitoring and re-assessment." Proceedings of ASME 2008 Pressure Vessels and Piping Conference, Paper No. PVP2008-61897 (2008).

16) Shah, V. N., and P.E. MacDonald. Aging and Life Extension of Major Light Water Reactor Components. Elsevier Science (1993).

17) Chopra, O., and G. Stevens. Effect of LWR Coolant Environments on the Fatigue Life of Reactor Materials. U.S. Nuclear Regulatory Commission Report No. NUREG/CR-6909, Revision 1 (2014).

18) Mohanty, S., W. Soppet, S. Majumdar, and K. Natesan. Tensile and Fatigue Testing and Material Hardening Model Development for 508 LAS Base Metal and 316 SS Similar Metal Weld under In-Air and PWR Primary Loop Water Conditions. Argonne National Laboratory Report ANL/LWRS-15/02 (2015) (doi:10.2172/1224989; http://www.osti.gov/scitech/servlets/purl/1224989).

19) Mohanty, S., W. Soppet, S. Majumdar, and K. Natesan. Environmental Effect on Evolutionary Cyclic Plasticity Material Parameters of 316 Stainless Steel: An Experimental \& Material Modeling Approach. Argonne National Laboratory Report ANL/LWRS-14/01 (2014) (doi:10.2172/1168233; http://www.osti.gov/scitech/servlets/purl/1168233).

20) Dassault Systèmes. "ABAQUS unified FEA: Complete solutions for realistic simulation." http://www.3ds.com/products-services/simulia/products/abaqus (2014).

21) Schulz, T. L. "Westinghouse AP1000 advanced passive plant." Nuclear Engineering and Design 236, no. 14 (2006): 1547-1557.

22) Cummins, W. E., M. M. Corletti, and T.L. Schulz. "Westinghouse AP1000 Advanced Passive Plant." Proceedings of ICAPP, Vol. 3, pp. 4-7 (2003).

23) Westinghouse Electric. Westinghouse AP600 Design Control Document. US-NRC Publication, ML003691016, http://pbadupws.nrc.gov/docs/ML0036/ML003691016.html (2000).

24) Westinghouse Electric. Westinghouse AP1000 Design Control Document. US-NRC Publication, ML11171A500, http://pbadupws.nrc.gov/docs/ML1117/ML11171A500.html (2011).

25) Cooke, C., and H. Spann. "Reactor vessel and reactor vessel internals segmentation at Zion Nuclear Power Station-13230." Proceedings of WM2013 Conference, Phoenix, Arizona, February 24 -28, 2013 (http://www.wmsym.org/archives/2013/papers/13230.pdf)

26) Westinghouse Electric. Westinghouse Technology Manual. Chapter 17, http://pbadupws.nrc.gov/docs/ML0230/ML023040268.pdf.

27) Gamble, R. "Evaluation of pressure-temperature limits for normal RPV startup and shutdown. EPRI-NRC Public Meeting, Rockville, MD, August 28, 2012 ((http://pbadupws.nrc.gov/docs/ML1224/ML12243A266.pdf ).

28) Betova, I., M. Bojinov, and T. Saario. Start-up and Shut-down Water Chemistries in Pressurized Water Reactors. Technical Research Centre of Finland, Report No. VTT-R00699-12 (2012) (http://www.vtt.fi/inf/julkaisut/muut/2012/VTT-R-00699-12.pdf). 
29) Westinghouse Electric. Westinghouse Technology Manual, Section 5.4, "Containment temperature, pressure, and combustible gas control systems" (http://pbadupws.nrc.gov/docs/ML1122/ML11223A222.pdf).

30) Gray, M. A., \& Verlinich, M. M. (2012). Guidelines for Addressing Environmental Effects in Fatigue Usage Calculations. Electric Power Research Institute Report EPRI1025823.

31) American Society of Mechanical Engineers (2010). ASME Boiler and Pressure Vessel Code, section III.

32) Mohanty, S., Majumdar, S., \& Natesan, K. (2016). Steam generator tube rupture simulation using extended finite element method. Nuclear Engineering and Design, 305, 697-705.

33) Reinhardt, L., J.A. Cordes, and D. Geissler. "Using co-simulation to extend the usage of XFEM." Proceedings of SIMULIA Customer Conference, 2011.

34) Han, D.-J., and S.-P. Park. "Evaluation of fracture toughness of pressure vessel steel using charpy impact test specimens." Nuclear Engineering and Technology 19, no. 1 (1987): 1-9.

35) U.S. Nuclear Regulatory Commission. "Crack in weld area of reactor coolant system hot leg piping at V. C. Summer.” U.S. NRC Letter Report, Information Notice 2000-017, 2000; Supplement 1, 2000; Supplement 2, 2001. (http://pbadupws.nrc.gov/docs/ML0105/ML010570353.pdf).

36) Dorner, H., \& Michel, E. (1976). "Reactor pressure vessel support arrangement." U.S. Patent No. 3,947,322. Washington, DC: U.S. Patent and Trademark Office.

37) Desmarchais, W. E. (1971). "Reactor vessel supports." U.S. Patent No. 3,583,429. Washington, DC: U.S. Patent and Trademark Office 


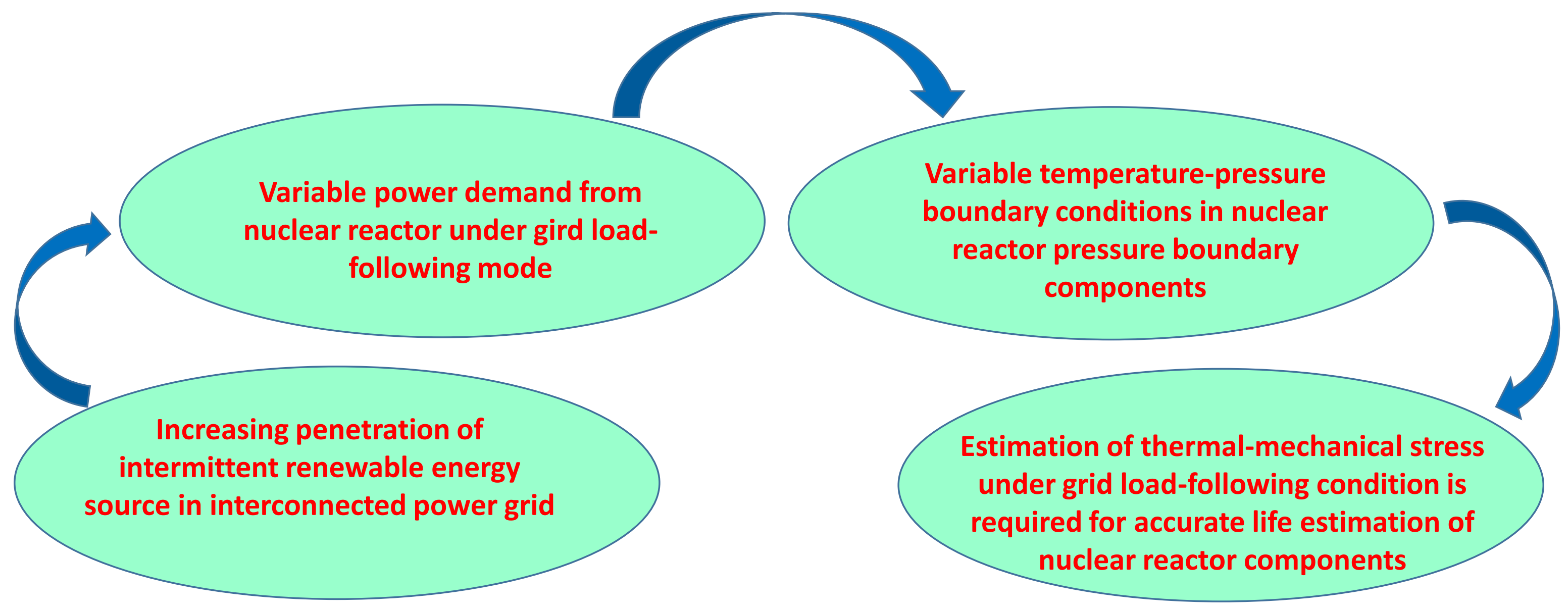

